\title{
Down-shifting Si-based layer for Si solar applications
}

\author{
L. Dumont ${ }^{\mathrm{a}}$, P. Benzo ${ }^{\mathrm{a}, 1}$, J. Cardin ${ }^{\mathrm{a}}$, I.-S. Yu ${ }^{\mathrm{b}}$, C. Labbé ${ }^{\mathrm{a}}$, P. Marie ${ }^{\mathrm{a}}$, C. Dufour ${ }^{\mathrm{a}}, \mathrm{G}$ Zatryb ${ }^{\mathrm{c}}$, \\ A. Podhorodecki ${ }^{\mathrm{c}}, \mathrm{F}$. Gourbilleau ${ }^{\mathrm{a}, *}$ \\ a CIMAP, Normandie Univ, ENSICAEN, UNICAEN, CEA, CNRS, 6 Bd Maréchal Juin, 14050 Caen Cedex 4, France \\ b Department of Materials Science and Engineering, National Dong Hwa University, Hualien 97401, Taiwan \\ c Department of Experimental Physics, Faculty of Fundamental Problems of Technology, Wroclaw University of Science and Technology, 50-370 Wroclaw, Poland
}

Keywords:

Silicon crystalline Solar Cell

Photovoltaic

Frequency conversion

Down Shifting

Rare Earth

Silicon Nitride

\begin{abstract}
A B S T R A C T
$\mathrm{SiN}_{\mathrm{x}}$ and $\mathrm{SiN}_{\mathrm{x}}: \mathrm{Tb}^{3+}$ thin layers were deposited by reactive magnetron co-sputtering with the objective of optimizing the light management in Si solar cells. Those Si-based layers are developed to be compatible with the $\mathrm{Si}$-PV technology. An efficient energy transfer between $\mathrm{SiN}_{\mathrm{x}}$ matrix and terbium ions $\left(\mathrm{Tb}^{3+}\right)$, enhancing this system absorption, has been demonstrated and optimized. The layer composition and microstructure as well as its optical properties have been analyzed with the aim of improving both its anti-reflective properties and its luminescence emission intensity. An optimized layer was obtained by co-sputtering of $\mathrm{Si}$ and $\mathrm{Tb}$ targets in a nitrogen rich atmosphere. The emission efficiency of the $\mathrm{SiN}_{\mathrm{x}}: \mathrm{Tb}^{3+}$ layer is compared to the one of previously optimized $\mathrm{SiO}_{\mathrm{x}} \mathrm{N}_{\mathrm{y}}: \mathrm{Tb}^{3+}$ layer. Finally we show how $\mathrm{SiN}_{\mathrm{x}}: \mathrm{Tb}^{3+}$ thin films may be integrated on top of Si solar cells and act simultaneously as a down-shifting layer and antireflective coating.
\end{abstract}

\section{Introduction}

Solar energy is one of the sustainable energies considered for the progressive replacement of fossil fuels in our society. However, to continuously reduce the cost per Watt, improving Solar Cell (SC) efficiency is essential. Despite Si-SC technology being currently the most used, it suffers from a low efficiency ranging from $12 \%$ to $20 \%$ depending on the quality level of the system. This low efficiency is mainly due to the energy mismatch between the solar spectrum and the $\mathrm{Si}$ bandgap. Indeed, only the photons with energy higher than the Si bandgap are absorbed by the $S C$. Moreover, the energy excess of those photons with respect to the bandgap energy is released into the matrix via transfer to phonons in a thermalization process. Consequently, an increase of $1{ }^{\circ} \mathrm{C}$ above $25^{\circ} \mathrm{C}$ leads to a decrease of the cell efficiency by around $0.65 \%[1-3]$. The rising temperature also leads to a faster aging of the cell. Another cause of the low efficiency limit is the fact that all the light received by the cell is not absorbed due to reflection of the incident light at the surface of the $S C$. Even while using light-trapping devices, Yablonovitch [4] demonstrated that a maximum achievable light path length enhancement of $4 n^{2}$ may be attained (with $n$ the refractive index of the bare $S C$ ).

As laboratory Si-SC efficiency is close its theoretical limit [5], one of the next steps for improving the single junction Si-SC efficiency consists in studying the management of the light within the $S C$. Some solutions are already implemented on $S C$ such as texturation or anti-reflective layers [5-7]. New solutions consisting in a frequency conversion of the light to adapt the solar spectrum to the cell bandgap are down-shifting $[8,9]$ and down/up-conversion layers [8,10-14]. Those frequency conversions are usually achieved by using rare earth-doped matrices. The up-conversion layer concerns the photons transparent for the Si-SC and thus is placed at the bottom of the cell. The down-conversion or down-shifting layers are deposited on top of the solar cells to improve the use of the incoming photons with an energy higher than the $\mathrm{Si}$ bandgap. In a down-conversion $(D C)$ layer, one $U V$ photon is transformed in two $I R$ photons having an energy just above the $S C$ bandgap. Thus the number of photons used by the cell increases while the thermalization decreases. Whereas a down-shifting (DS) layer will absorb one $U V$ photon and reemit a single photon with an energy above the $S C$ bandgap. Thus the down-shifted photons wavelengths better match the spectral photo-absorptivity response of the Si-SC. In addition the thermalization process will take place in the $D S$ layer instead of the $S C$. Thus by thermally isolating the $D S$ layer from the $S C$, with transparent materials, the thermalization could be partially decoupled from the cell which reduces the entropy flow and may increase the cell efficiency as described by Landsberg efficiency [15]. A $D S$ layer is composed of a matrix containing one rare earth ion whereas in a down-conversion layer, two or more rare earth ions are incorporated in the matrix. Many matrices and rare earth ions have been

\footnotetext{
* Corresponding author.

E-mail address: fabrice.gourbilleau@ensicaen.fr (F. Gourbilleau).

${ }^{1}$ Present address: CEMES, 29 rue Jeanne Marvig, 31055 Toulouse Cedex 4.
} 
studied in both cases [9,16-19].

The goal of our study consists in developing Si-based frequency conversion layers compatible with the $S i$-SC industry process in order to lower the production cost and increase the $S C$ efficiency. Moreover, such $D S$ - or $D C$-layer should be stable, which was not the case with most of the matrices studied. Indeed, they were either degraded during the $S C$ processing or damaged by high energy photons during sun exposure [14]. In addition, some of those used materials were toxic because of the presence of fluorine [20] or of heavy metals such as cadmium [21], or lead [22]. Following this reasoning, various studies using a silicon oxynitride matrix, $\mathrm{SiO}_{\mathrm{x}} \mathrm{N}_{\mathrm{y}}$, doped with terbium ions $\left(\mathrm{Tb}^{3+}\right)$ have been carried out [23-25]. However, the presence of oxygen favors the rare earth clusters formation that is detrimental to an intense emission. Our study then focuses on the terbium-doped silicon nitride matrix, $\mathrm{SiN}_{\mathrm{x}}: \mathrm{Tb}^{3+}$, such a system being free of oxygen to promote rare earth ions incorporation [26]. $\mathrm{SiN}_{\mathrm{x}}$ has been chosen as host matrix since it is already used as anti-reflective layer on industrial $S i-S C$ which is a way to develop new approach keeping a low production cost of the $S C$. Besides, such a host matrix should be an efficient sensitizer to the rare earth ions that have a weak absorption cross-section (below $2 \times 10^{-21} \mathrm{~cm}^{2}$ [27]) in silicon based matrices. Consequently, such a host matrix should have a high absorption in the $U V$ range as well as efficient sensitizing properties toward $\mathrm{Tb}^{3+}$ ions while keeping its antireflective properties.

In this paper we will describe the optimizations of the undoped $\operatorname{SiN}_{\mathrm{x}}$ and $\mathrm{SiN}_{\mathrm{x}}: \mathrm{Tb}^{3+}$ layers. The goal is to develop a layer that presents at the same time an efficient $D S$ frequency conversion process, and antireflective property. Thus the composition and microstructure, as well as the optical properties of these systems will be studied.

\section{Material and methods}

The layers studied were deposited on p-type $250 \mu$ m-thick [001] 2" silicon ( $\mathrm{Si}$ ) substrates by radio-frequency reactive magnetron cosputtering in a nitrogen-rich plasma. The matrix composition $(\mathrm{Si} / \mathrm{N}$ ratio) was tuned by varying the $\mathrm{Ar} / \mathrm{N}_{2}$ ratio $\left(r N_{2}\right)$ of the gas flux injected or the plasma pressure $(P)$. In the case of the $\mathrm{Tb}^{3+}$-doped system, the rare earth ions incorporation was controlled by the power density applied on the $\mathrm{Tb}$ target $\left(R F P_{T b}\right)$. This later was varied between 0.3 and $1.8 \mathrm{~W} / \mathrm{cm}^{2}$. For all the undoped- and $\mathrm{Tb}^{3+}$-doped $-\mathrm{SiN}_{\mathrm{x}}$ deposited layers, the target power density applied on the silicon target was fixed at $4.5 \mathrm{~W} / \mathrm{cm}^{2}$ in agreement with previous studies [28]. For all the samples, the deposition temperature was fixed at $200{ }^{\circ} \mathrm{C}$ while the deposition time was adjusted to obtain $90 \mathrm{~nm}$-thick films whatever the deposition conditions. After deposition, the samples were annealed during $1 \mathrm{~h}$ by classical thermal annealing (CTA) at $850{ }^{\circ} \mathrm{C}$, under $\mathrm{N}_{2}$ flow.

The composition of the studied layers has been investigated by means of Fourier Transform Infrared (FTIR) measurements. They were performed at room temperature using a Thermo Nicolet Nexus 750 II spectrometer working in the $4000-400 \mathrm{~cm}^{-1}$ range, with a resolution of $5 \mathrm{~cm}^{-1}$. By fitting the obtained spectra with Gaussian functions, the vibration band positions were obtained.

Both the thickness and the complex refractive index of the studied layers were determined from ellipsometry measurements employing a UVISEL Jobin-Yvon ellipsometer with an incident angle of $66.2^{\circ}$. The experimental $I_{c}$ and $I_{s}$ ellipsometry spectra were recorded on a $1.5-5 \mathrm{eV}$ range with $0.01 \mathrm{eV}$ resolution. The parameters (thickness and $\mathrm{n}$ ) are determined by fitting the experimental data by a dispersion law derived from the Forouhi-Bloomer model [29] of amorphous semiconductors using the DeltaPsi2 software.

In order to study the emission and excitation properties, photoluminescence $(P L)$ and photoluminescence excitation $(P L E)$ experiments were performed at room temperature on the films. Specifically, the $P L$ setup included a Lot-Oriel $1 \mathrm{~kW}$-Xenon lamp connected to an OMNI300 monochromator used as a tunable light source. The $P L$ spectra were recorded with a Hamamatsu (R5108) photomultiplier tube after the dispersion of the $P L$ signal by a MSH 300 OMNI monochromator. The detection system was locked in with a SR830 amplifier referenced at the excitation light beam chopped frequency. The $P L$ and $P L E$ spectra obtained were normalized by the sample thickness and the PLE spectra are also corrected by the excitation intensity.

The PL decays were measured using modified Quanta Master system from Photon Technology International (PTI). A pulsed $266 \mathrm{~nm}$ line of an actively Q-switched diode-pumped solid state YAG:Nd laser (Elforlight Ltd.) was used in this experiment as the excitation source. The PL decay traces were measured at the emission wavelength of $545 \mathrm{~nm}$, corresponding to the main ${ }^{5} \mathrm{D}_{4^{-}}{ }^{7} \mathrm{~F}_{5}$ transition of $\mathrm{Tb}^{3+}$ ions. The time resolution about $1 \mu$ s is small enough to resolve correctly the $\mathrm{Tb}^{3+}$ PL lifetimes.

A simulation program based on the transfer matrix method (TMM) [30] was run based on the deduced ellipsometric parameters (complex refractive index of a layer, substrate, superstrate and stack of layers, and thicknesses) to calculate the absorbance $A$, reflectance $R$, and transmittance $T$ of the fabricated $D S$ films deposited on top of a silicon $S C$. In addition, values representing the layer and its interaction with the AM1.5 solar spectrum [31] are defined. The absorbance efficiency $\left(A_{\text {eff }}\right)$ is defined by the integration of the absorbance $A$ convoluted by the solar irradiance spectrum $\left(I_{A M 1.5}\right)$ and normalized by the integrated solar irradiance spectrum $\left(I_{A M 1.5}\right)$ :

$A_{e f f}=\frac{\int_{\lambda_{\min }}^{\lambda_{\max }} A(\lambda) I_{A M 1.5}(\lambda) d \lambda}{\int_{\lambda_{\min }}^{\lambda_{\max }} I_{A M 1.5}(\lambda) d \lambda}$

The reflectance $\left(R_{\text {eff }}\right)$, and transmittance $\left(T_{\text {eff }}\right)$ efficiencies are defined similarly using the reflectance $R$, and the transmittance $T$ respectively $A_{\text {eff, }} R_{\text {eff }}$ and $T_{\text {eff }}$ represent the fraction of the sunlight that is absorbed, reflected and transmitted respectively by the layer over a given spectral range. Those values may be compared over different wavelength ranges and allow an easy comparison between samples.

The light emission and propagation in our samples were studied thanks to an $3 * 3$ extended transfer matrix method (ETMM) coupled with electric dipole emitters [32-34]. This method uses the ellipsometric parameters (refractive indexes and thicknesses) of the sample and the surrounding media. With this method we can deduce the emission distribution as a function of the wavelength and the emission angle in each considered medium. The $\mathrm{Tb}^{3+}$ spectral line shape was assumed to be described by Gaussian functions representing the ${ }^{5} D_{4}$ to ${ }^{7} F_{6}$ and ${ }^{5} D_{4}$ to ${ }^{7} F_{5}$ energy transitions of the $\mathrm{Tb}^{3+}$ ions (Fig. 1). PL spectra were obtained by the integration over emission angles in the conversion layer, air, and silicon material substrate (wafer or $S C$ ). A supplementary integration over the bandwidth led to the luminescence integrated over the spectral range $I^{P L}{ }_{i}$ in each of the three media $\mathrm{i}$

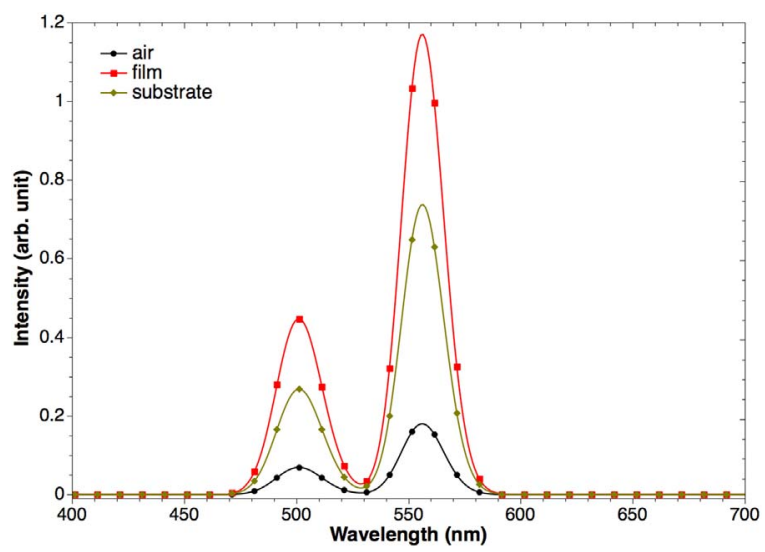

Fig. 1. Modeled $\mathrm{Tb}^{3+} P L$ spectra recorded in the three media, only the two more intense peaks/bands representing the ${ }^{5} D_{4}$ to ${ }^{7} F_{6}$ and ${ }^{5} D_{4}$ to ${ }^{7} F_{5}$ energy transitions are considered. 
(layer, air, and silicon) and consequently to the global emission properties:

$I_{i}^{P L}=\int_{T o t} I_{i}(\lambda) d \lambda$

The integrated luminescence efficiencies $\eta_{i}^{\text {lum }}$ in each medium is defined by the following equation:

$\eta_{i}^{\text {lum }}=\frac{I_{i}^{P L}}{I_{\text {air }}^{P L}+I_{\text {layer }}^{P L}+I_{\text {substrate }}^{P L}}$

\section{Results and discussion}

In this section, the composition and microstructure of the two systems $\left(\mathrm{SiN}_{\mathrm{x}}\right.$, and $\left.\mathrm{SiN}_{\mathrm{x}}: \mathrm{Tb}^{3+}\right)$ will be first studied, followed by the analysis of their optical properties. Finally, an optimized $\mathrm{Tb}^{3+}$-doped $\mathrm{SiN}_{\mathrm{x}}$ layer will be presented and compared with our previous work on $\mathrm{SiO}_{\mathrm{x}} \mathrm{N}_{\mathrm{y}}: \mathrm{Tb}^{3+}$ film. The internal quantum efficiency (IQE) of a Si-SC covered by this optimized DS layer will also be detailed.

\section{1. $\operatorname{SiN}_{x}$ matrix}

\subsubsection{Microstructure}

Fig. 2 exhibits transmittance FTIR spectra of a typical $\operatorname{SiN}_{\mathrm{x}}$ layer conducted at both normal (in red) and Brewster (65 ) (in black) angles. In both spectra, we can see the presence of two vibration bands peaking at $1121 \mathrm{~cm}^{-1}$ and $847 \mathrm{~cm}^{-1}$. Ordinarily, only the TO band at $847 \mathrm{~cm}^{-1}$ may be seen under normal incidence analysis, but the amorphous character of the layers leads to a possible contribution of the $L O$ peaks even under such incidence angle [35]. As expected, there is no signature of bands corresponding to either Si-O bond at around 1200 $\mathrm{cm}^{-1}$, Si-H bond between 2200 and $2090 \mathrm{~cm}^{-1}$, or N-H bond between 3320 and $2500 \mathrm{~cm}^{-1}$.

The absence of Si-O related bands around $1200 \mathrm{~cm}^{-1}$ confirms that the two bands peaking at $1121 \mathrm{~cm}^{-1}$ and $847 \mathrm{~cm}^{-1}$ may only originate

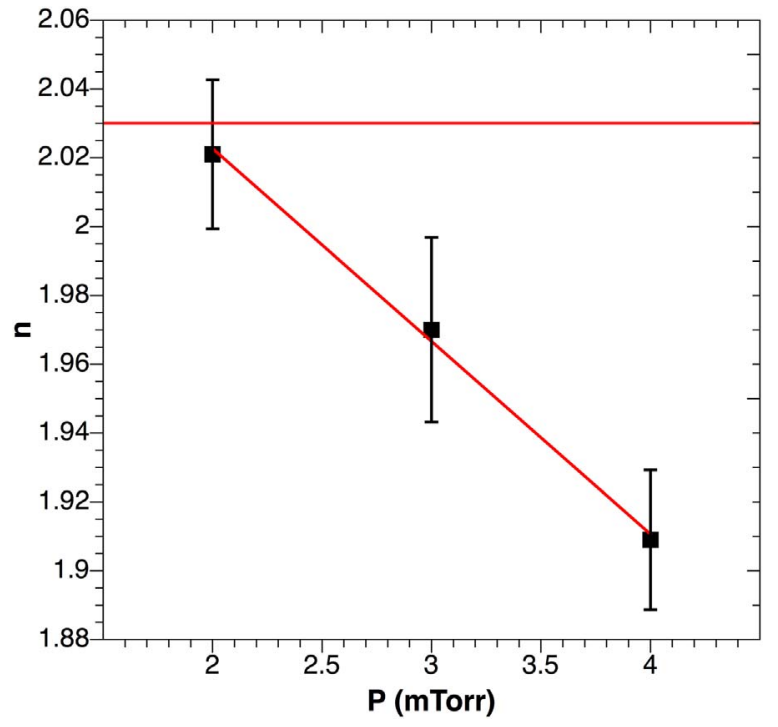

Fig. 3. Refractive index of as grown $\mathrm{SiN}_{\mathrm{x}}$ films as a function of the plasma pressure, $P$, for a nitrogen ratio, $r N_{2}$, fixed at $20 \%$. The red line corresponds to the stoichiometric material $\mathrm{Si}_{3} \mathrm{~N}_{4}$ refractive index value. (For interpretation of the references to color in this figure legend, the reader is referred to the web version of this article).

\section{from the Si-N bond.}

The inset of Fig. 2 displays the evolution of the position of the $L O$ band of the Si-N bond (blue dots) as well as the refractive index at $1.95 \mathrm{eV}$ (black squares) as a function of the nitrogen ratio $r N_{2}$. When $r N_{2}$ increases, the $L O_{S i-N}$ band position shifts toward the high wavenumbers (blueshift) by $10 \mathrm{~cm}^{-1}$ which is a small relative variation, while the refractive index at $1.95 \mathrm{eV}$ value decreases. Such evolution has already been observed by Debieu et al. [28] over a larger $r N_{2}$ domain ranging from $0 \%$ to $29 \%$ and therefore with a larger blueshift variation of $50 \mathrm{~cm}^{-1}$. This smaller $L O_{S i-N}$ peak blueshift is consequently consistent with a smaller $r N_{2}$ range. According to the works of Huang

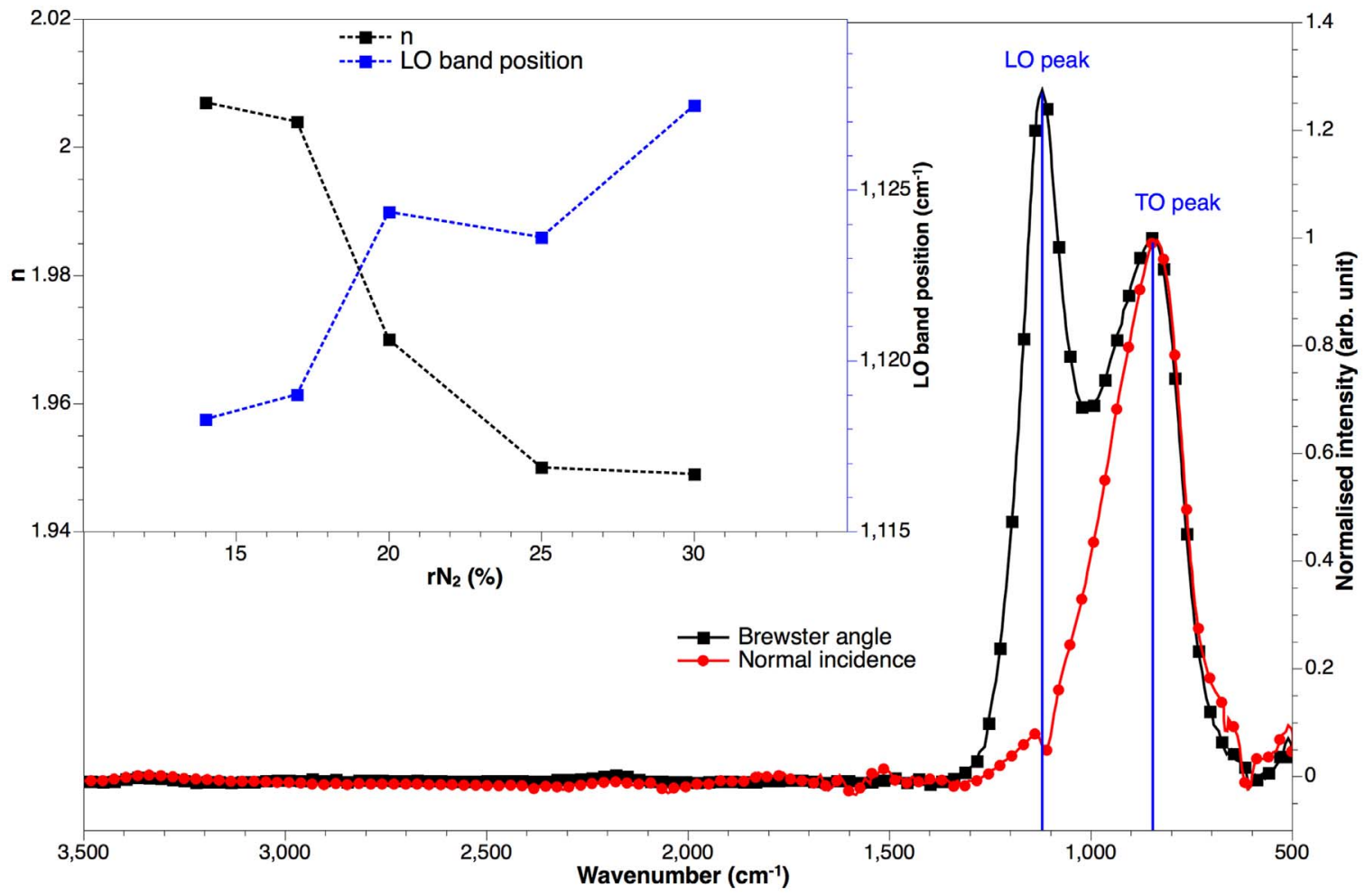

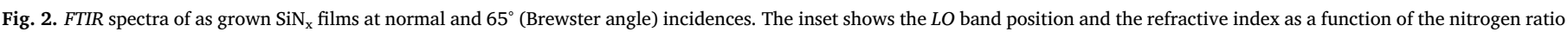
$\left(r N_{2}\right)$ for a plasma pressure (P) fixed at 3 mTorr. 


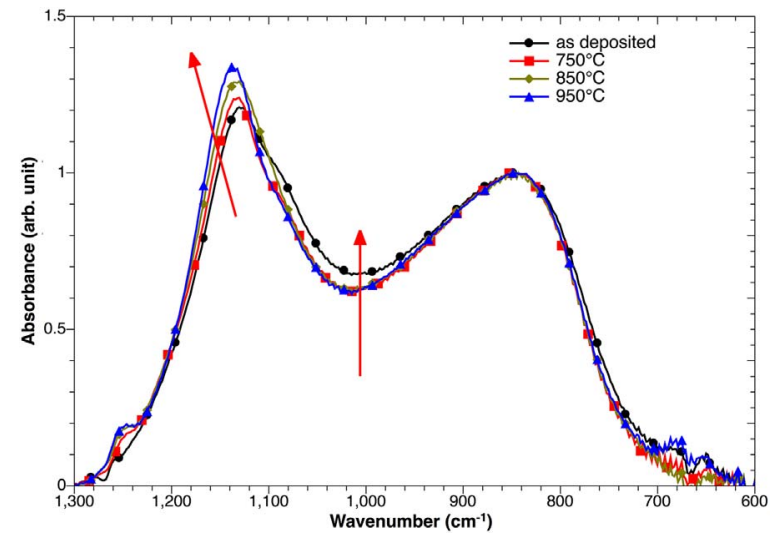

Fig. 4. FTIR spectra at Brewster angle for different annealing temperatures.

et al. [36] and Debieu et al. [28] on O- or H-free $\operatorname{SiN}_{\mathrm{x}}$ films, such a blueshift of the $L O_{S i-N}$ vibration band can be ascribed to a decrease of the $[\mathrm{Si} / \mathrm{N}]$ ratio. Such matrix composition change leads to a shortening of the Si-N bond [37], or to an increase in the matrix disorder due to nitrogen excess. These phenomena are also compatible with the observed decrease of the refractive index at $1.95 \mathrm{eV}$ (inset Fig. 2).

The effect of the plasma pressure $P$ on the microstructural characteristic of the grown layer has been also investigated for $r N_{2}$, fixed at $20 \%$. Fig. 3 shows the decrease of the refractive index at $1.95 \mathrm{eV}$ by 0.11 (4 times the measurement uncertainty) while $P$ increases. Such
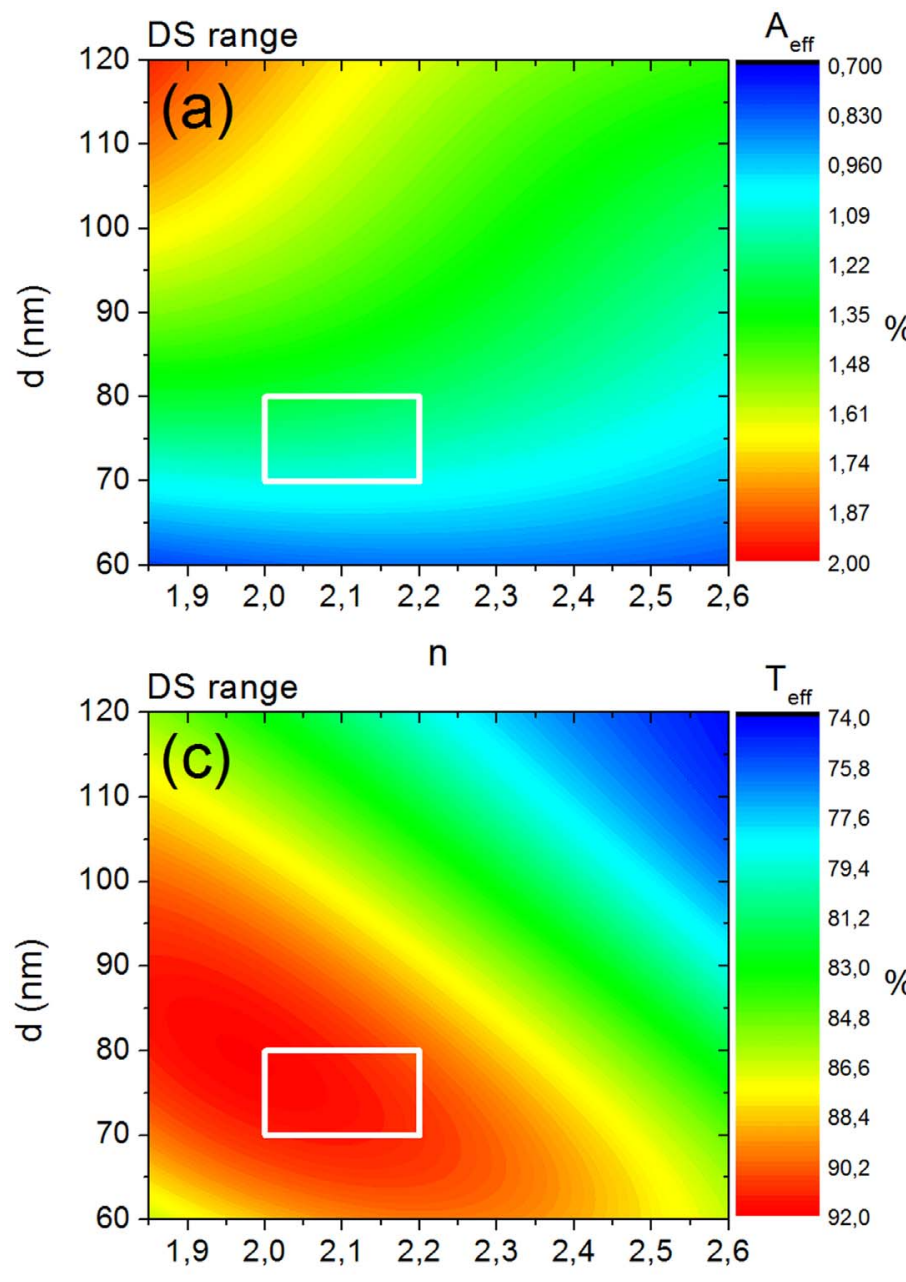

$\mathrm{n}$ evolution can be ascribed to a decrease of the [Si/N] ratio due an incorporation of nitrogen with higher plasma pressure as detailed above according to the work of W.R. Knolle as well as of Gardeniers et al. $[38,39]$.

After deposition, the films are submitted to a CTA treatment during one hour in a nitrogen flux. The influence of the annealing temperature on the microstructure of the films has been studied and the corresponding FTIR spectra registered under Brewster incidence are presented in Fig. 4. Increasing annealing temperature favors the increase of $L O_{S i-N}$ band intensity with a concomitant shift of its position to higher wavenumbers. Considering that the film composition remains unchanged during this process, this evolution is attributed to the decrease of the disorder resulting from the reorganization of the matrix upon annealing. Such a decrease of the matrix disorder is confirmed by the lower overlapping of $T O_{S i-N}$ and $L O_{S i-N}$ bands around $1000 \mathrm{~cm}^{-1}$ [28].

\subsubsection{Optical properties}

The development of downshifting layer should meet important criteria prior to be used in a SC. Due to the low absorption cross section of the rare earth ions mentioned above, $\mathrm{Tb}^{3+}$ ions require the presence of efficient sensitizers able to absorb the solar energetic photons and transfer their energy to the rare earth ions for promoting at least the excitation of the electron from the ${ }^{7} F_{6}$ to the ${ }^{5} D_{4}$ energy level. As the downshifting layer will be placed on the top of the Si solar cell, it should require the following three criteria: (i) a low absorbance of photons having an energy lower than $2.54 \mathrm{eV}(488 \mathrm{~nm})$ to allow their conversion within the Si-SC but should also emit the downshifted
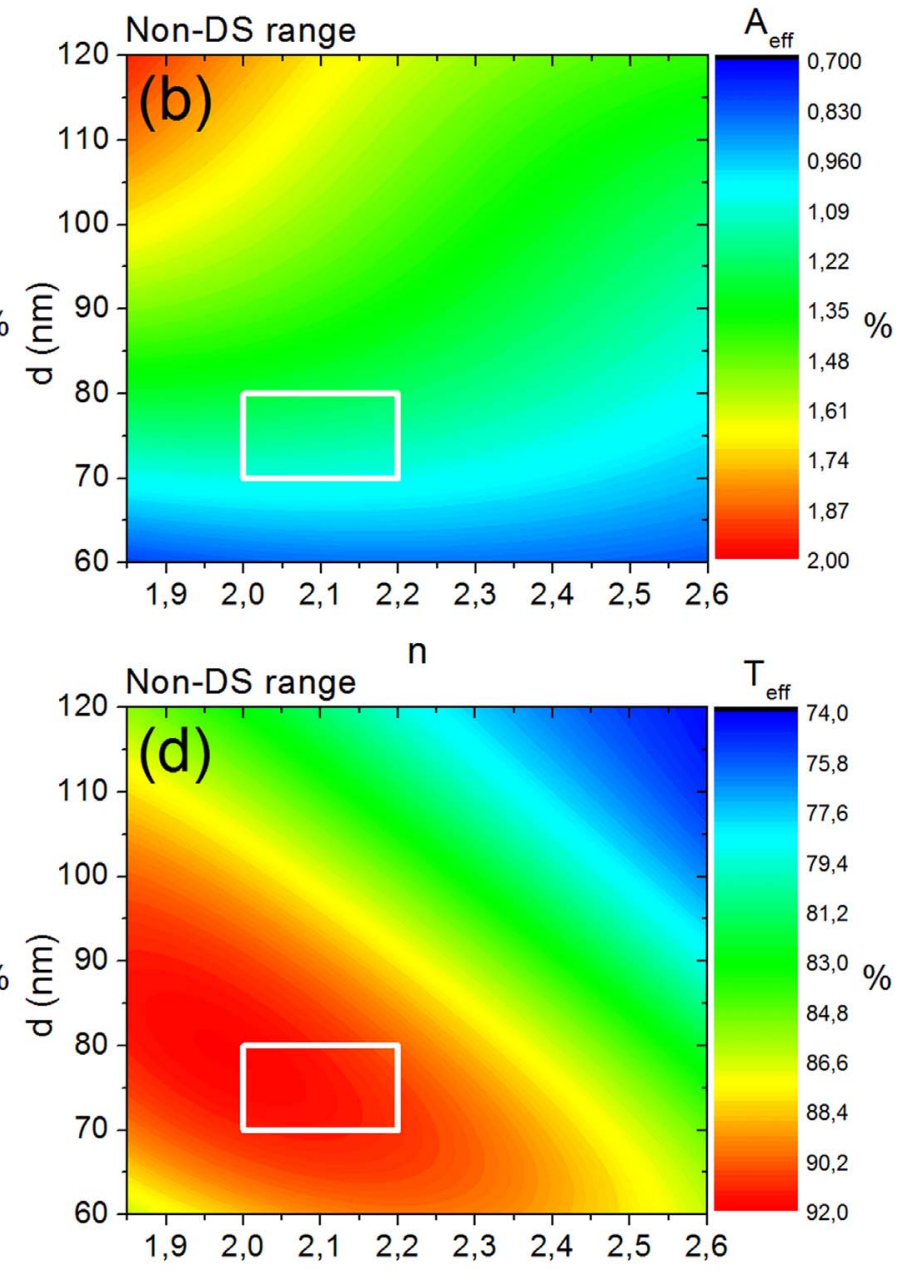

$\mathrm{n}$

Fig. 5. $A_{\text {eff }}$ as a function of $\mathrm{n}$ and $\mathrm{d}$ in the $D S$ (a) and Non-DS (b) ranges, and $T_{\text {eff }}$ as a function of $n$ and $d$ in the DS (c) and Non-DS (d) ranges. 
photons with a high extraction into the $S C$, (ii) a low absorbance and a high transmittance of photons in the 1.1-2.54 eV energy range, and (iii) a low reflectance in order to collect as much as possible the light into the $\mathrm{SiN}_{\mathrm{x}}$ layer-Si-SC system.

3.1.2.1. Refractive index properties. Before depositing our layers, we study the $R_{\text {eff }}, A_{\text {eff, }}$, and $T_{\text {eff }}$ described in the "Material and methods" part and that represent the calculated reflectance, absorbance, and transmittance efficiencies as a function of the static refractive index $n$ and the thickness of the layer $d$ for a constant extinction coefficient $(k=0.008)$.

Two wavelength domains have to be defined before any analyses. One where the doped-SiN $\mathrm{x}_{\mathrm{x}}$ layer will play its role of frequency conversion, which corresponds to the $300-488 \mathrm{~nm}$ range noted $D S$, and one where it should be as transparent as possible. This later ranges from 488 to $1200 \mathrm{~nm}$ is noted Non-DS.

As previously mentioned, we seek a layer with a high absorbance and low transmittance in the DS range while having low absorbance and high transmittance in the Non-DS range. In addition, the reflectance has to be low on the whole spectral range.

Fig. 5 displays $A_{\text {eff }}$ as a function of $n$ and $d$ in the DS (Fig. 5a) and Non-DS (Fig. $5 b$ ) ranges as well as $T_{\text {eff }}$ as a function of $\mathrm{n}$ and $\mathrm{d}$ in the $D S$ (Fig. 5c) and Non-DS (Fig. 5d) ranges. The absorbance and the transmittance should thus ideally be gate functions. However the monotonous behavior of the refractive index of the materials used does not allow such feature. A compromise has to be done between high absorbance in the $D S$ range and high transmittance in the Non-DS one. Then the thickness should be smaller than $100 \mathrm{~nm}$ and the refractive index at $1.95 \mathrm{eV}$ smaller than 2.2 .

Fig. 6 shows $R_{\text {eff }}$ as a function of $n$ and $d$ in the total range (DS and Non-DS ranges). The couple $n=2.0$ and $d=80 \mathrm{~nm}$ shows the lower reflectance. However, in order to keep such high anti-reflective properties with a varying refractive index, the thickness has to be tuned consequently. In this range of $n$ and $d$, an increasing $n$ should be compensated by a decreasing $d$. Thus, the couple $n=2.2$ and $d=70 \mathrm{~nm}$ also leads to high anti-reflective properties. By examining Fig. 6, we may determine that the layer thickness should not go over $100 \mathrm{~nm}$ with a preference for $80-70 \mathrm{~nm}$ and the refractive index at $1.95 \mathrm{eV}$ should stay between 2.0 and 2.2 (white squares on Figs. 5 and 6).

After determining by modeling the optimal characteristics of the future $D S$ layers, $\operatorname{SiN}_{\mathrm{x}}$ host matrix is deposited varying $P$ and $r N_{2}$. Reflectance, absorbance, and transmittance curves of the deposited layers are deduced from the ellipsometric experimental measurements as a function of $r N_{2}$. However, it is difficult to compare those curves for different layers. Thus, we will use the absorbance $A_{\text {eff }}$, reflectance $R_{e f f}$,

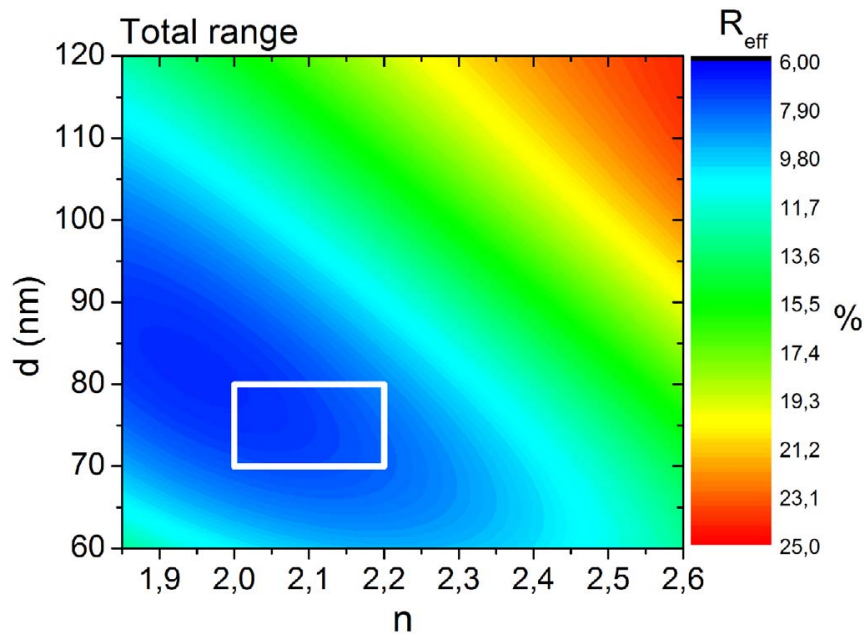

Fig. 6. $R_{\text {eff }}$ as a function of $\mathrm{n}$ and $\mathrm{d}$ in the full range (DS and Non-Ds ranges) $(300-1200 \mathrm{~nm})$. and transmittance $T_{\text {eff }}$ efficiencies described in the "Material and methods" part. As explained above, those values allow to describe the interaction between the light of the AM1.5 solar irradiance spectrum and the DS layers on different spectral ranges, and therefore to let an easier comparison. $A_{\text {eff }}$ and $T_{\text {eff }}$ are analyzed in the $D S$ range $(300-488 \mathrm{~nm})$ and the Non-DS range $(488-1200 \mathrm{~nm})$. Fig. 7 exhibits $A_{\text {eff }}$ and $T_{\text {eff }}$ of the layers for different $r N_{2}$ for a $P$ fixed at $3 \mathrm{mTorr}$ (Fig. $7 a$ and $c$ ) and different $P$ for a $r N_{2}$ fixed at $20 \%$ (Fig. $7 b$ and $d$ ). The red lines represent the $\mathrm{Si}_{3} \mathrm{~N}_{4}$ reference. It is important to note that the values of $A_{\text {eff }}$ and $T_{\text {eff }}$ are similar in the two ranges due to the monotonous refractive index evolution over the full spectral range.

Regarding the effect of the nitrogen ratio $r N_{2}, A_{\text {eff }}$ increases and $T_{\text {eff }}$ decreases with the increase of $r N_{2}$. This behavior is more pronounced for the layers with a $r N_{2}$ higher than $20 \%$. For those last two layers the absorbance is very high, and the transmittance very low, in the $D S$ range but also in the non-DS one which is a major drawback for solar cell applications. For $r N_{2}$ of $14 \%$ and $17 \%$, the absorbance is closer to the one of the $\mathrm{Si}_{3} \mathrm{~N}_{4}$ reference which is interesting for the Non-DS part but useless in the DS one since it will not favor the sensitization of the rare earth ions.

The calculated reflectance efficiency $\left(R_{\text {eff }}\right)$ in the full range $\left(300-1200 \mathrm{~nm}\right.$ ) is reported in Fig. 8 as a function of $r N_{2}$ (Fig. 8a), and of $P$ (Fig. $8 b$ ). Those values are compared to the $R_{\text {eff }}$ of a $\mathrm{Si}_{3} \mathrm{~N}_{4}$ reference layer (red line). This figure shows that the layers displaying the lower reflectance are those fabricated with $P=4$ mTorr (when $\mathrm{rN}_{2}=20 \%$ ) and $r N_{2}=25 \%$ (when $\mathrm{P}=3$ mTorr). However, considering our reference, the layers fabricated with $P=2$ and $3 \mathrm{mTorr}$ and $r N_{2}=20 \%$ have a $R_{\text {eff }}$ close to the red line and still present high antireflective characteristics. The pressure $P$ does not seem to influence significantly the $R_{\text {eff }}$ while the $r N_{2}$ values have to be between $20 \%$ and $25 \%$ to produce layers meeting one of the above-mentioned criteria. The best trade-off for a sample with low $R_{\text {eff }}$ and, high $A_{\text {eff }}$ in the $D S$ range and low $A_{\text {eff }}$ in the Non-DS range is obtained for a nitrogen ratio $r N_{2}$ of $20 \%$ and a plasma pressure $P$ of 3 mTorr.

Regarding the effect of the plasma pressure $P$, the best layer with high absorbance and low transmittance efficiencies in the DS part is the one deposited with a $P$ of 4 mTorr. However, its absorbance efficiency is also very high, and its transmittance efficiency very low, in the non-DS part of the spectrum that will strongly decrease the efficiency of the $\mathrm{Si}$ solar cell. The analysis of the two other samples deposited with a $P$ of 2 mTorr and 3 mTorr present lower absorbance and higher transmittance efficiencies in the non-DS range with a slightly higher absorbance and lower transmittance efficiencies for the 2 mTorr grown layer (by $4 \%$ and $0.72 \%$ respectively). However, they also present similar lower absorbance efficiencies in the $D S$ one with respect to the 4 mTorr grown layer. Thus, $P$ and $r N_{2}$ values under 3 mTorr and 20\% respectively have to be chosen to produce layers meeting one of the above-mentioned criteria, even if in the non-DS part, such a $\operatorname{SiN}_{\mathrm{x}}$ layers absorbs more photons than the $\mathrm{Si}_{3} \mathrm{~N}_{4}$ one.

The increase of absorbance efficiency with $r N_{2}$ and $P$ may be linked to the increase of nitrogen content in the matrix which allow a higher nitrogen defects concentration $[40,41]$. The resulting nitrogen defects states in the gap of the matrix will lead to larger photons absorption.

According to the absorbance and transmittance efficiencies, the criteria previously mentioned (low reflectance on the whole solar spectrum, high absorbance and low transmittance in the $D S$ range, and low absorbance and high transmittance in the Non-DS range) are reached in the range of $r N_{2}$ between $14 \%$ and $20 \%$, and $P$ below 3 mTorr. However, the reflectance efficiencies show (Fig. 8) that it might be interesting to also look for $r N_{2}$ between $20 \%$ and $25 \%$ to improve the anti-reflective properties of the layers. The best compromise is thus the layer deposited with a nitrogen ratio $r N_{2}$ of $20 \%$ and a plasma pressure $P$ of 3 mTorr.

3.1.2.2. Photoluminescence. Fig. 9 shows photoluminescence $(P L)$ results of $\mathrm{SiN}_{\mathrm{x}}$ layers measured as a function of the plasma pressure $P$ 

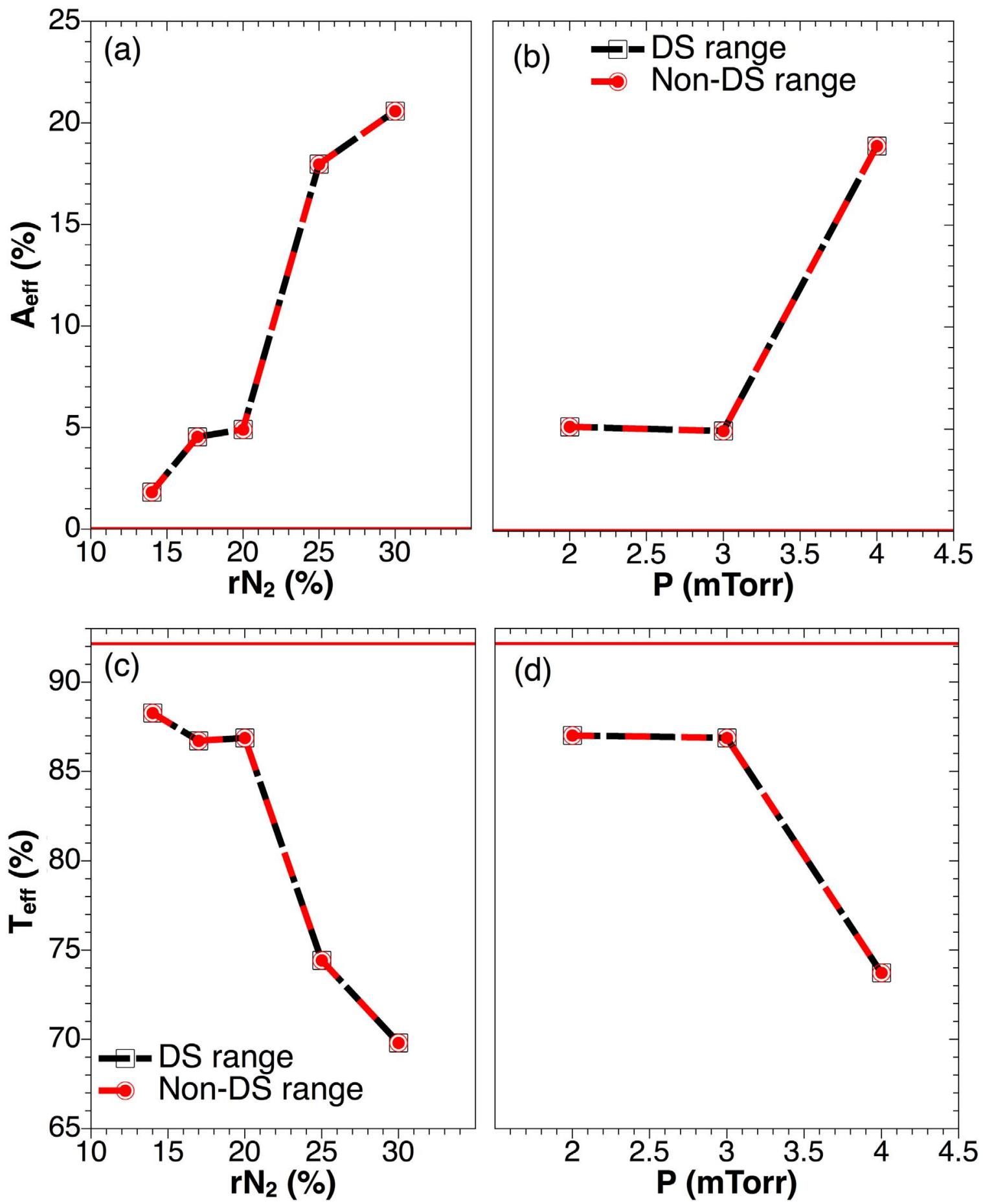

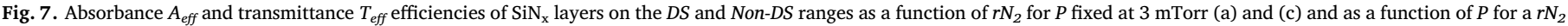

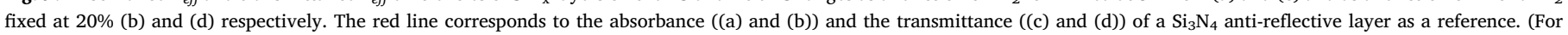
interpretation of the references to color in this figure legend, the reader is referred to the web version of this article).

and the nitrogen ratio $r N_{2}$. The $P L$ of the annealed $\mathrm{SiN}_{\mathrm{x}}$ layers demonstrates the existence of distinct states in the matrix bandgap. Only the states that underwent radiative de-excitation are revealed. A multi-peaks fit (modeling peaks thanks to Gaussian curves) shows that the $P L$ spectra are composed of three to four peaks depending on the deposition parameters. The position of those broad peaks due to the density of states of the defects is displayed in Fig. $9 b$.

A correspondence is found between the experimental (Fig. 9b) and theoretical energy transitions [42-47] that may thus be associated to specific electronic transitions, as reported on Fig. 10. However, it is important to note that the energy levels associated to the $\equiv \mathrm{Si}-\mathrm{Si} \equiv \sigma$ and $\sigma^{*}$ as well as $=\mathrm{N}^{-}$centers are close to the conduction and valence bands $(0.5 \mathrm{eV}$ or less). In consequence the broad observed emission band arises from the transitions between those various energy levels:

- The peak (1), at $370 \mathrm{~nm}(3.3 \mathrm{eV})$ may correspond to the $3.1-3.6 \mathrm{eV}$ transitions associated to the electronic transition occurring from $\left(E_{c}\right.$ or $\left.\equiv \mathrm{Si}-\mathrm{Si} \equiv \sigma^{*}\right)$ to $\left(=\mathrm{N}_{2}{ }^{\circ}\right)$ and from $\left(=\mathrm{N}_{4}{ }^{+}\right)$to $\left(=\mathrm{N}^{-}, \equiv \mathrm{Si}-\mathrm{Si} \equiv \sigma\right.$, or $E_{v}$ ) (red arrows in Fig. 10). With $E_{c}$ the energy level of the conduction band with the lowest energy and $E_{v}$ the energy level of the valence band with the highest energy.

- The peak (2), at $440 \mathrm{~nm}(2.8 \mathrm{eV})$ may correspond to the $2.5-3.0 \mathrm{eV}$ 

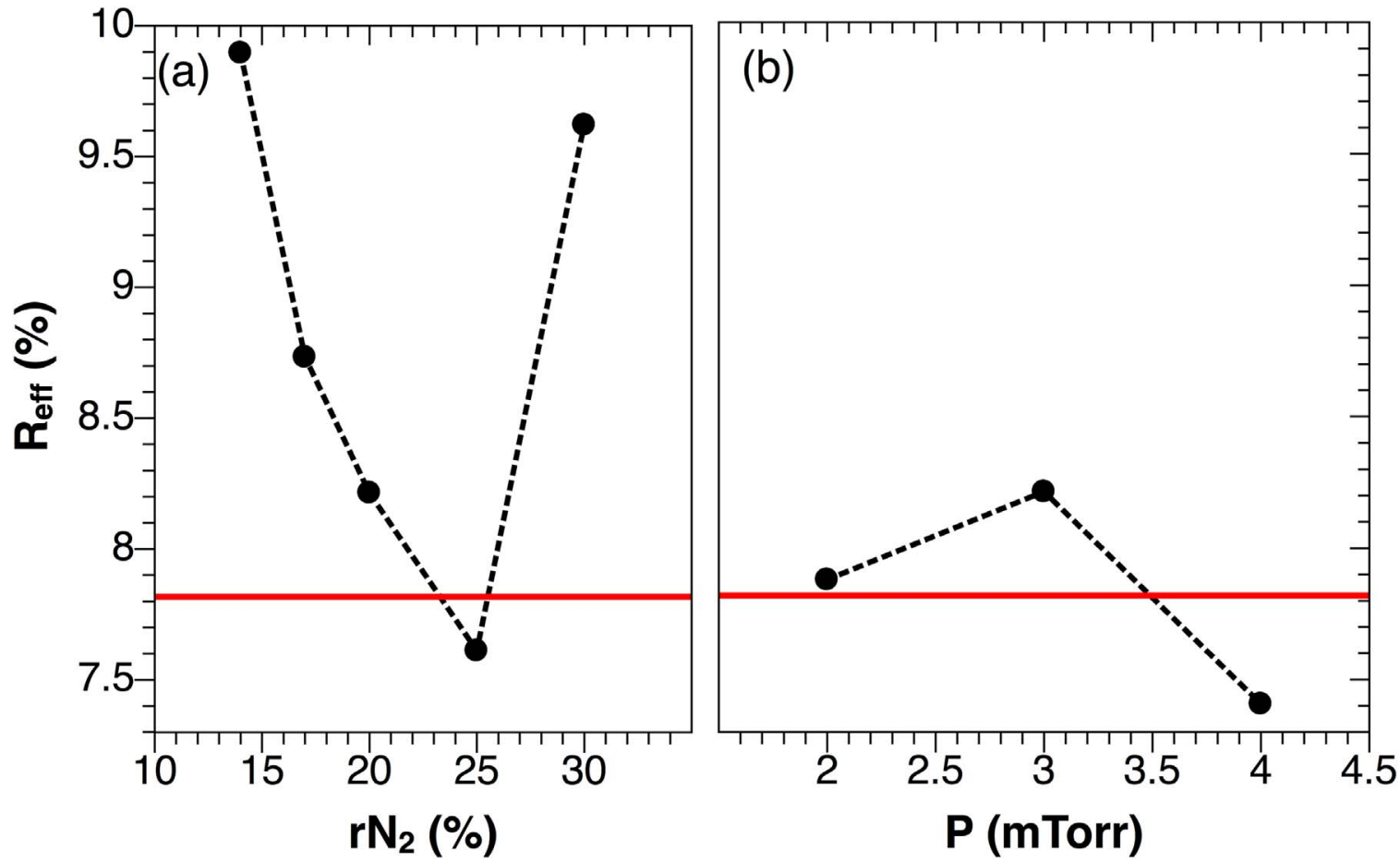

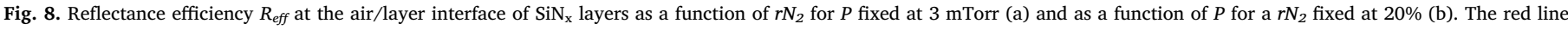

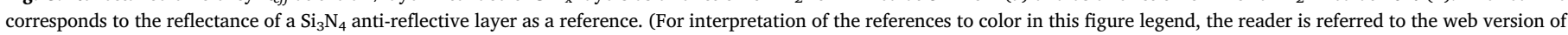
this article).

transitions associated to the electronic transition occurring from $\left(\equiv \mathrm{Si}^{-}\right)$to $\left(=\mathrm{N}^{-}, \equiv \mathrm{Si}-\mathrm{Si} \equiv \sigma\right.$, or $\left.E_{v}\right)$ (green arrow in Fig. 10).

- The peak (3), at $490 \mathrm{~nm}(2.5 \mathrm{eV})$ may correspond to the $2.2-2.7 \mathrm{eV}$ transitions associated to the electronic transition occurring from $\left(E_{c}\right.$ or $\left.\equiv \mathrm{Si}-\mathrm{Si} \equiv \sigma^{*}\right)$ to $\left(\equiv \mathrm{Si}^{\circ}\right)$ and from $\left(\equiv \mathrm{Si}^{\circ}\right)$ to $\left(=\mathrm{N}^{-}, \equiv \mathrm{Si}-\mathrm{Si} \equiv \sigma\right.$, or
$E_{v}$ ) (violet arrows in Fig. 10). It also might correspond to the 2.0-2.4 eV associated to the electronic transition occurring from ( $E_{c}$ or $\left.\equiv \mathrm{Si}-\mathrm{Si} \equiv \sigma^{*}\right)$ to $\left(\equiv \mathrm{Si}^{-}\right.$) (violet arrows in Fig. 10).

- The peak (4), at $585 \mathrm{~nm}(2.1 \mathrm{eV})$ may correspond to $1.3-1.8 \mathrm{eV}$ transitions associated to the electronic transition occurring from $\left(\mathrm{E}_{\mathrm{c}}\right.$
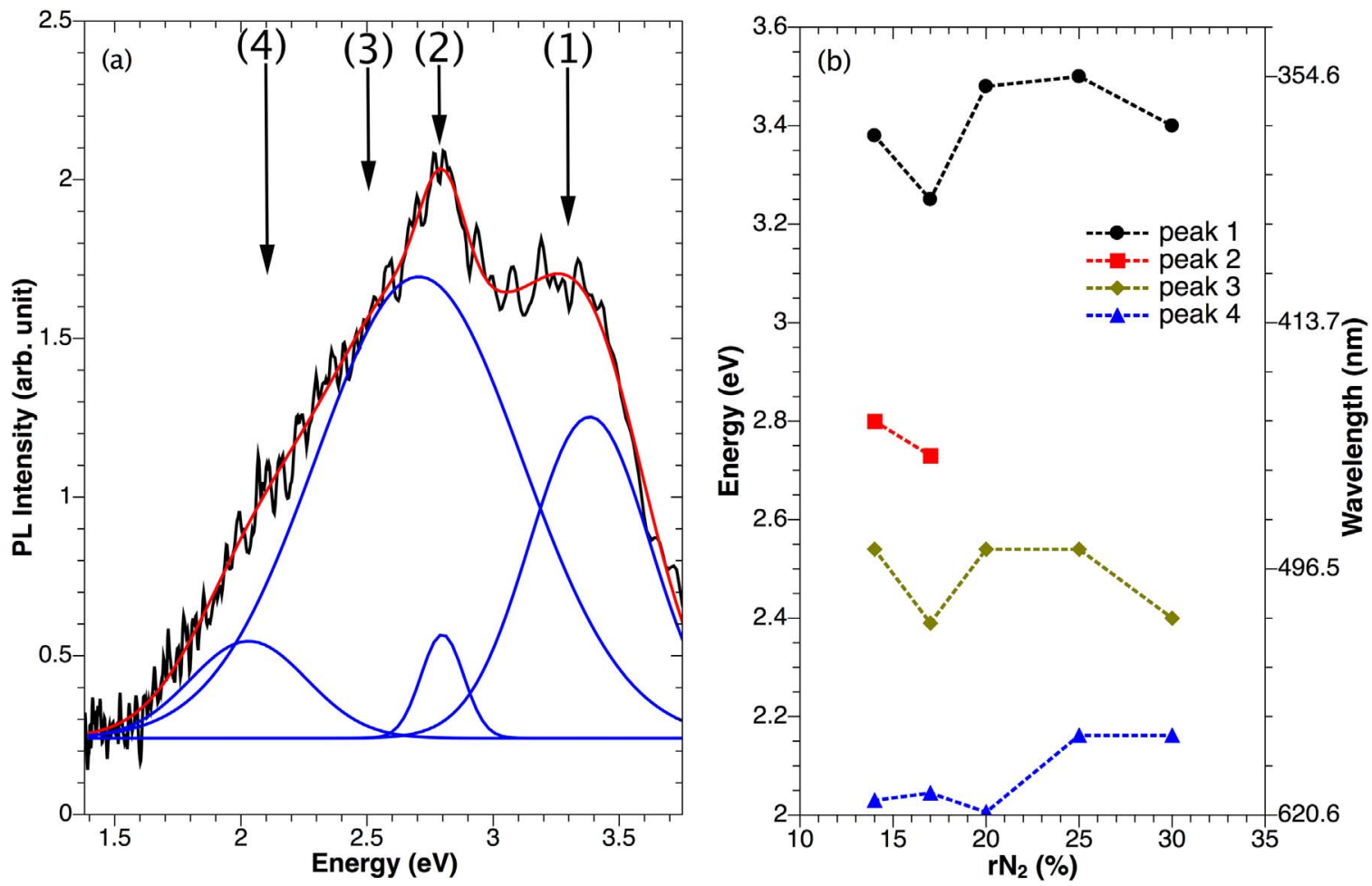

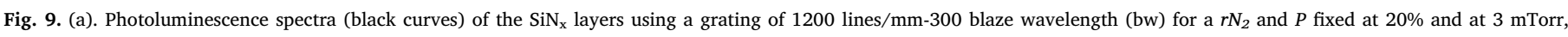

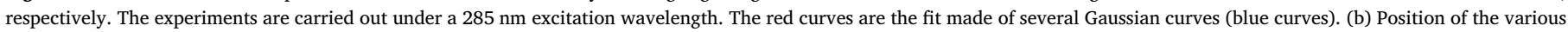
peaks as a function of $r N_{2}$. (For interpretation of the references to color in this figure legend, the reader is referred to the web version of this article). 


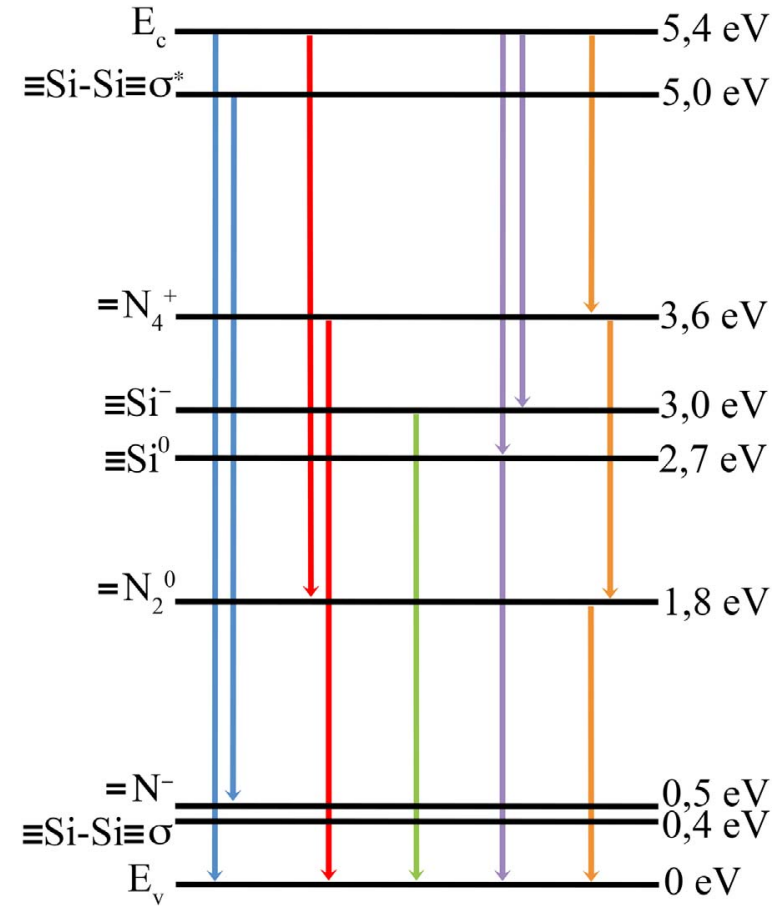

Fig. 10. Energy level diagram of the $\operatorname{SiN}_{\mathrm{x}}$ matrix with the energy level transitions observed in the literature [42-46] and the energy transfers possible and observed on Fig. 9.

or $\left.\equiv \mathrm{Si}-\mathrm{Si} \equiv \sigma^{*}\right)$ to $\left(=\mathrm{N}_{4}{ }^{+}\right)$, from $\left(=\mathrm{N}_{2}{ }^{\circ}\right)$ to $\left(=\mathrm{N}^{-}\right)$, or/and from $\left(\equiv \mathrm{Si}-\mathrm{Si} \equiv \sigma\right.$, or $\mathrm{E}_{\mathrm{v}}$, and $=\mathrm{N}_{4}{ }^{+}$) to $\left(=\mathrm{N}_{2}{ }^{\circ}\right.$ ) (orange arrows in Fig. 10).

For the layer deposited with $r N_{2}$ of $14 \%$, the PL intensity reaches 3.9 arb.unit and decreases by a factor 2 for $r N_{2}$ equal to $17 \%$ or $20 \%$. For highest value (25\% and $30 \%), P L$ peaks are close to the background noise and therefore not distinguishable. The higher $P L$ intensity is obtained for a $P$ of 3 mTorr, whereas for the other values the $P L$ signal is not distinguishable.

Note that the second peak (red dots on Fig. $9 b$ ), associated to the electronic transition occurring from $\left(\equiv \mathrm{Si}^{-}\right)$to $\left(=\mathrm{N}^{-}, \equiv \mathrm{Si}-\mathrm{Si} \equiv \sigma\right.$, or $\left.E_{v}\right)$ (at $440 \mathrm{~nm}$ or $2.8 \mathrm{eV}$ ), appears only for the $14 \%$ and $17 \%$ nitrogen ratio. This may be due to the decreasing silicon content proportionally to the nitrogen one that will decrease the number of Si-Si bonds in favor of the Si-N ones. As a result, the silicon related defects $\left(\equiv \mathrm{Si}^{-}\right)$and $(\equiv \mathrm{Si}-$ $\mathrm{Si} \equiv \sigma^{*}$ and $\sigma$ ) number will decrease and lead to the disappearance of the electronic recombinations occurring from those levels (peak (2)).

Following the same reasoning the electronic transitions from $\left(E_{c}\right.$ or $\left.\equiv \mathrm{Si}-\mathrm{Si} \equiv \sigma^{*}\right)$ to $\left(\equiv \mathrm{Si}^{-}\right)$(violet arrow to the right) is less probable than the ones from $\left(E_{c}\right.$ or $\left.\equiv \mathrm{Si}-\mathrm{Si} \equiv \sigma^{*}\right)$ to $\left(\equiv \mathrm{Si}^{\circ}\right)$ and from $\left(\equiv \mathrm{Si}^{\circ}\right)$ to $\left(=\mathrm{N}^{-}\right.$, $\equiv \mathrm{Si}-\mathrm{Si} \equiv \sigma$, or $E_{v}$ ). Indeed, the third peak is present for all the $r N_{2}$ values while the second peak that features the $\equiv \mathrm{Si}^{-}$energy level is present only for the lowest $r N_{2}$ values.

Thus, the defect states in the bandgap of $\operatorname{SiN}_{\mathrm{x}}$ matrix are at the origin of the emissions at around $370 \mathrm{~nm}(3.34 \mathrm{eV}), 440 \mathrm{~nm}(2.81 \mathrm{eV})$, and $490 \mathrm{~nm}(2.52 \mathrm{eV})$. These energies are in resonance with the energy levels of $\mathrm{Tb}^{3+}$ ions $\left({ }^{5} G_{6},{ }^{5} D_{3^{-}}{ }^{7} F_{6},{ }^{5} D_{3^{-}}{ }^{7} F_{4},{ }^{5} D_{4^{-}}{ }^{7} F_{6}\right)$. This makes defect states from $\mathrm{SiN}_{\mathrm{x}}$ matrix potential sensitizers of $\mathrm{Tb}^{3+}$ ions via nonradiative transfer energy.

\section{2. $\mathrm{SiN}_{x}: \mathrm{Tb}$ system}

In the following, the optimized $\mathrm{Tb}^{3+}$ content in $\mathrm{SiN}_{\mathrm{x}}$ host matrix will be investigated through the PL intensity of the $\mathrm{Tb}^{3+}$ ions peaks. As shown on Fig. 11a, four emission peaks can be observed corresponding to the transitions from the ${ }^{5} D_{4}$ to the ${ }^{7} F_{\mathrm{i}}$ levels as presented on Fig. $11 b$. Note that the emission spectrum has been achieved under a low photon flux $\left(1.9 \times 10^{15}\right.$ photons $\left./ \mathrm{cm}^{2}\right)$ excitation at $300 \mathrm{~nm}$ for the $\mathrm{Tb}^{3+}$ ions which has a low absorption cross section below $2 \times 10^{-21} \mathrm{~cm}^{2}$ as reported in $[27,46]$. Such a result evidences an efficient indirect excitation of $\mathrm{Tb}^{3+}$ ions which may witness a sensitization of the $\mathrm{Tb}^{3+}$ ions by defect states of the matrix. Such an excitation process has already been evidenced in $\mathrm{Tb}^{3+}$-doped $\mathrm{SiO}_{\mathrm{x}} \mathrm{N}_{\mathrm{y}}$ and $\mathrm{Tb}-\mathrm{Si}_{\mathrm{x}} \mathrm{O}_{\mathrm{y}}$ systems $[23,24]$.

The influence of the $\mathrm{Tb}$ incorporation on the emission properties of the $\mathrm{SiN}_{\mathrm{X}}: \mathrm{Tb}^{3+}$ layer is presented in Fig. 12 in which the PL spectra recorded in the $330-720 \mathrm{~nm}$ range are reported for different $R F$ power densities applied on the $\mathrm{Tb}$ target. The left part of the scale is related to the emission of the host matrix, ranging between 360 and $460 \mathrm{~nm}$ while the right part of the scale corresponds to the $\mathrm{Tb}^{3+}$ emission in the $460-720 \mathrm{~nm}$ range. All the layers have been annealed at $850{ }^{\circ} \mathrm{C}$ during one hour under a pure nitrogen flux. The $P L$ of $T b$-free $\mathrm{SiN}_{\mathrm{x}}$ matrix is also reported on Fig. 12 showing a weak emission below $490 \mathrm{~nm}$. In Tbdoped matrix, the $P L$ associated to the defect states disappeared (Fig. 12) contrary to what was observed for non-doped matrix (Fig. 9a). This behavior suggests that an energy transfer may occur from the matrix defect states to the $\mathrm{Tb}^{3+}$ ions. In the $460-720 \mathrm{~nm}$ range, the increasing power density applied on the Tb target $R F P_{T b}$ favors the emission intensity of the $\mathrm{Tb}^{3+}$ ion which reaches its maximum for $0.45 \mathrm{~W} / \mathrm{cm}^{2}$ before decreasing and totally disappears for the highest $R F P_{T b}$ applied $\left(1.8 \mathrm{~W} / \mathrm{cm}^{2}\right)$. Since the $\mathrm{Tb}^{3+}$ lifetime (Inset Fig. 12) shows a constant value of about $620 \mu$ s for $R F P_{T b}$ up to $0.45 \mathrm{~W} / \mathrm{cm}^{2}$, the observed increase of the $\mathrm{Tb}^{3+}$ emission intensity up to $0.45 \mathrm{~W} / \mathrm{cm}^{2}$ can be associated with the increase of optically active $\mathrm{Tb}^{3+}$ ions.

Above $0.45 \mathrm{~W} / \mathrm{cm}^{2}$, the decrease of intensity with $R F P_{T b}$ is attributed either to a concentration quenching process due to rare earth ions clustering $[48,49]$ migrate or coupling $\mathrm{Tb}^{3+}$ ions with non radiative centers. This later point is confirmed by both the lifetime (inset of Fig. 12) and the FTIR measurements reported on Fig. 13. In the former, the terbium lifetime of the ${ }^{5} D_{4}-{ }^{7} F_{5}$ transition remains constant (around $620 \mu \mathrm{s}$ ) up to $R F P_{T b}=0.45 \mathrm{~W} / \mathrm{cm}^{2}$. Indeed, below such $R F P$, the $\mathrm{Tb}^{3+}$ ions incorporation does not favor the creation of non-radiative de-excitation paths. After the $R F P_{T b}$ reaches values higher than $0.45 \mathrm{~W} / \mathrm{cm}^{2}$, the observed decrease of the $\mathrm{Tb}^{3+}$ lifetime (from $620 \mu$ s to $360 \mu s$ and $180 \mu$ s) is an evidence of the formation of two new kinds of non-radiative de-excitation channels. The first would be defects in the matrix that can trap the photons. The second would be an energy migration process between $\mathrm{Tb}^{3+}$ ions that become close enough to transfer energy among themselves and enhances the probability to reach a trap. In the FTIR measurements, the increase of $R F P_{T b}$ favors the overlapping of $T O_{S i-N}-L O_{S i-N}$ bands around $1000 \mathrm{~cm}^{-1}$ as well as the decrease and the shift of the $L O_{S i-N}$ peak (Fig. 13). Such a feature is the signature of an increasing disorder and thus an increasing number of defects that may be responsible for the observed $P L$ emission quenching and emission decay time decrease. Thus our optimum settings leading to the higher $\mathrm{Tb}^{3+} P L$ intensity are $0.45 \mathrm{~W} / \mathrm{cm}^{2}$ for the $\mathrm{Tb}$ target power density with a nitrogen rate of $20 \% \mathrm{rN}_{2}$, and a plasma pressure of 3 mTorr.

Once the energy transfer from the host matrix to the $\mathrm{Tb}^{3+}$ ions has been proposed, its mechanism is detailed. A photoluminescence excitation (PLE) spectrum of the Tb-doped system was measured for a $545 \mathrm{~nm}$ detection wavelength $\left({ }^{5} D_{4} \rightarrow{ }^{7} F_{6}\right.$ transition $)$ and displayed in Fig. 14. It can be seen that the doped system is mainly excited in the range of $240-290 \mathrm{~nm}(5.2-4.3 \mathrm{eV})$ and decreases then to the limit of detectability for excitation wavelengths longer than $335 \mathrm{~nm}(3.7 \mathrm{eV})$. This energy range may be associated with electronic transitions occurring from $\left(E_{c}\right.$ or $\left.\equiv \mathrm{Si}-\mathrm{Si} \equiv \sigma^{*}\right)$ to $\left(=\mathrm{N}^{-}, \equiv \mathrm{Si}-\mathrm{Si} \equiv \sigma\right.$, or $\left.E_{v}\right)$. The broad energy distribution of electronic levels at the origin of energy transfer results in a broad PLE band. It is worth mentioning that the Full Width at Half Maximum (FWHM) of the PLE band is much broader than the FWHM of typical $f$ - $d$ absorption bands of rare earth ions, which is another evidence for indirect excitation of these ions. 


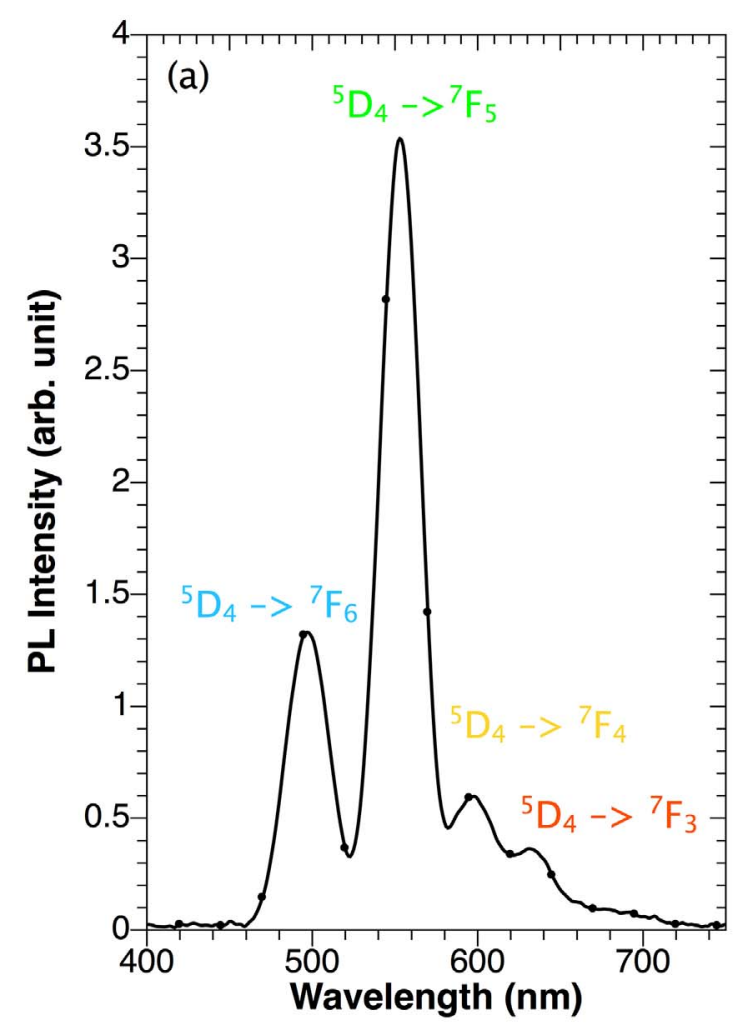

(b)

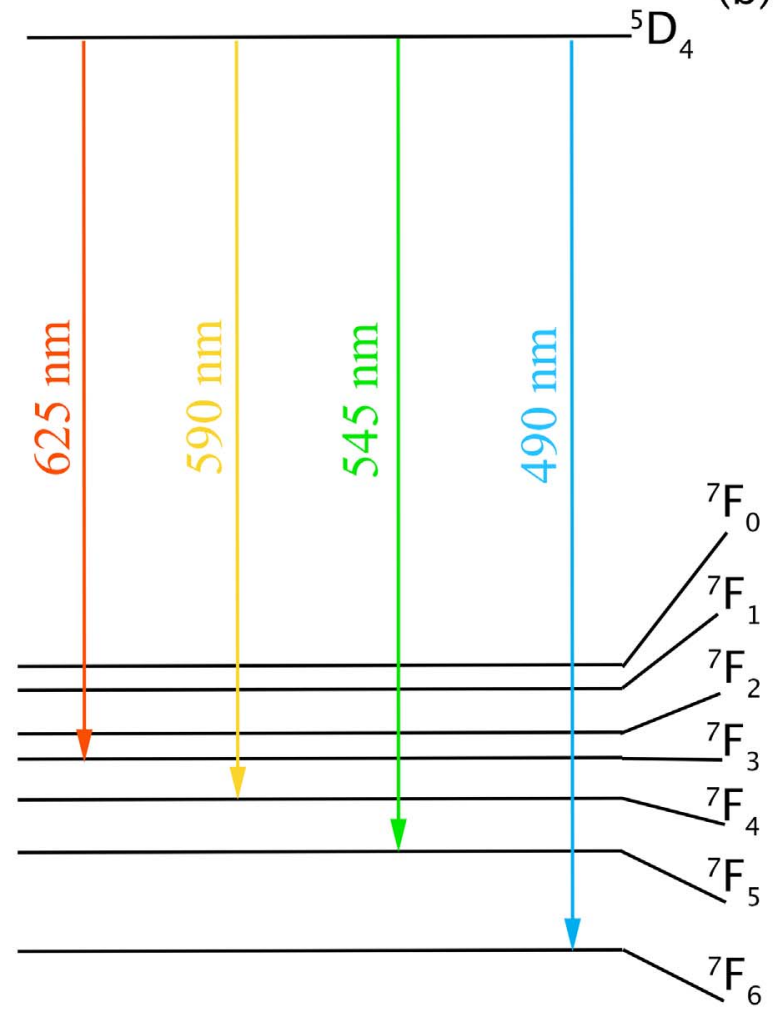

Fig. 11. (a) $P L$ spectrum of a Tb-doped $\mathrm{SiN}_{\mathrm{x}}$ under $300 \mathrm{~nm}$ excitation wavelength. (b) Energy level scheme of the $\mathrm{Tb}^{3+}$ ions.
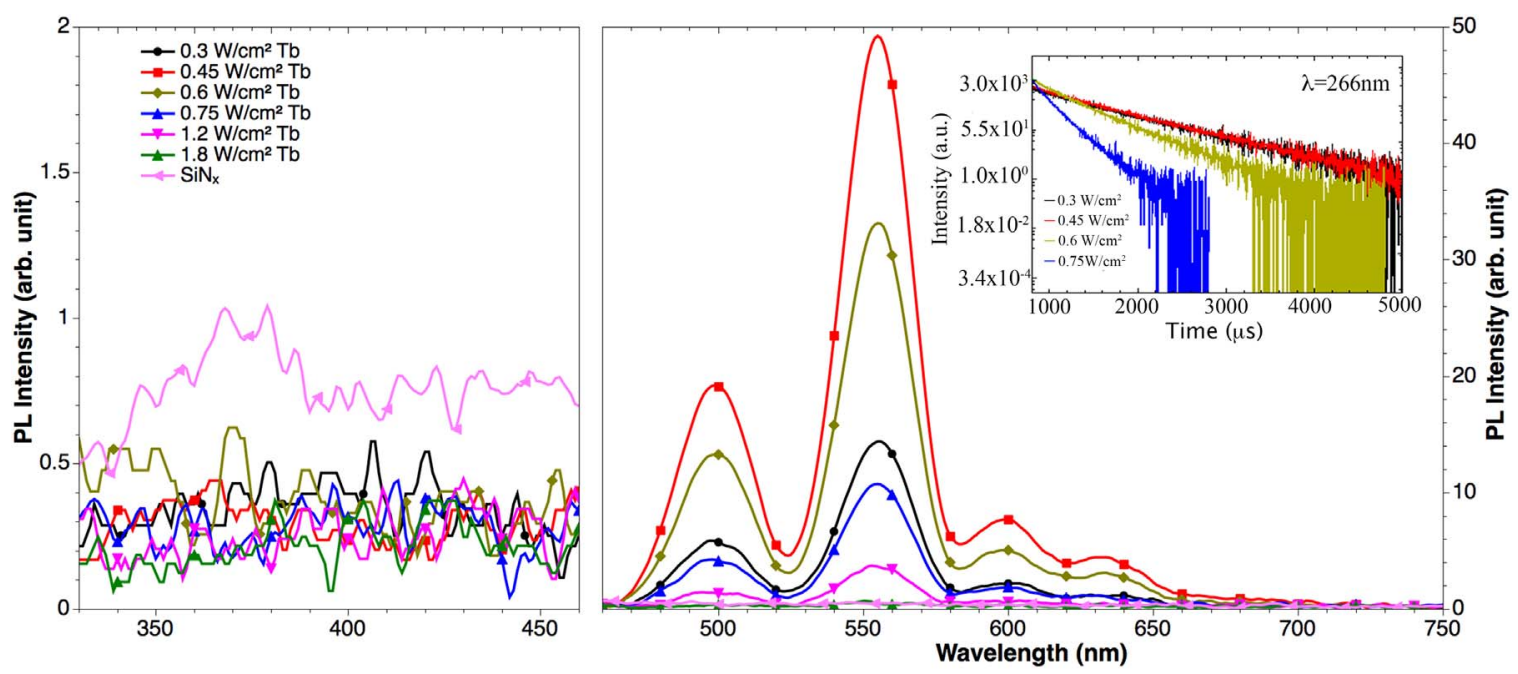

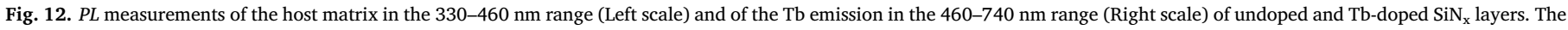

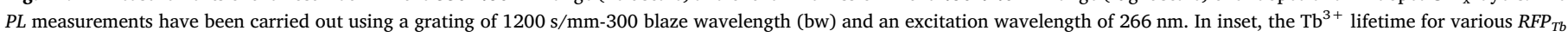
are exposed.

Fig. 14 also shows that the $\mathrm{Tb}^{3+}$ ions, due to their discrete energy structure, are excited mostly in their high energy levels such as the $4 f_{7} 5 d$ energy band and the ${ }^{5} H_{6,7,8}$ and ${ }^{5} H_{6,7,8}$ energy levels. This excitation occurs via energy transfer originating from the electronic transition from $\left(E_{c}\right.$ or $\left.\equiv \mathrm{Si}-\mathrm{Si} \equiv \sigma^{*}\right)$ to $\left(=\mathrm{N}^{-}, \equiv \mathrm{Si}-\mathrm{Si} \equiv \sigma\right.$, or $\left.E_{v}\right)$. The $\mathrm{Tb}^{3+}$ ions then undergo non-radiative de-excitation till reaching the ${ }^{5} D_{4}$ energy level from which the four characteristic radiative transitions $\left({ }^{5} D_{4} \rightarrow^{7} F_{x}\right.$ with $x=3,4,5$, and 6$)$ take place.

\subsection{Comparison of the $\mathrm{SiN}_{x}: \mathrm{Tb}^{3+}$ and $\mathrm{SiO}_{x} \mathrm{~N}_{y}: \mathrm{Tb}^{3+}$ systems}

The optimized $\mathrm{Tb}^{3+}$-doped $\mathrm{SiN}_{\mathrm{x}}$ layer obtained is compared to an optimized $\mathrm{Tb}^{3+}$-doped layer made with a silicon oxynitride matrix, $\mathrm{SiO}_{\mathrm{x}} \mathrm{N}_{\mathrm{y}}$ previously studied in our team [25]. The $\mathrm{Tb}^{3+}$ ions $P L$ peaks at $285 \mathrm{~nm}$ excitation wavelength of our optimized sample is found to be 2.3 times more intense than the optimized sample obtained on the $\mathrm{SiO}_{\mathrm{x}} \mathrm{N}_{\mathrm{y}}: \mathrm{Tb}^{3+}$ system (Fig. 15). However, considering an application to Si-SCs, the main parameter is not the light that is extracted toward the air but the light extracted toward the substrate, i.e. the $S C$. As such value is difficult to access experimentally, we calculated it based on ETMM method detailed in Material and methods part (\$2) and on experimental $P L$ data recorded in the air.

It has been shown [50] that the $\mathrm{Tb}^{3+} P L$ intensity in the air, $I_{\text {air }}^{P L}$, is given by: 


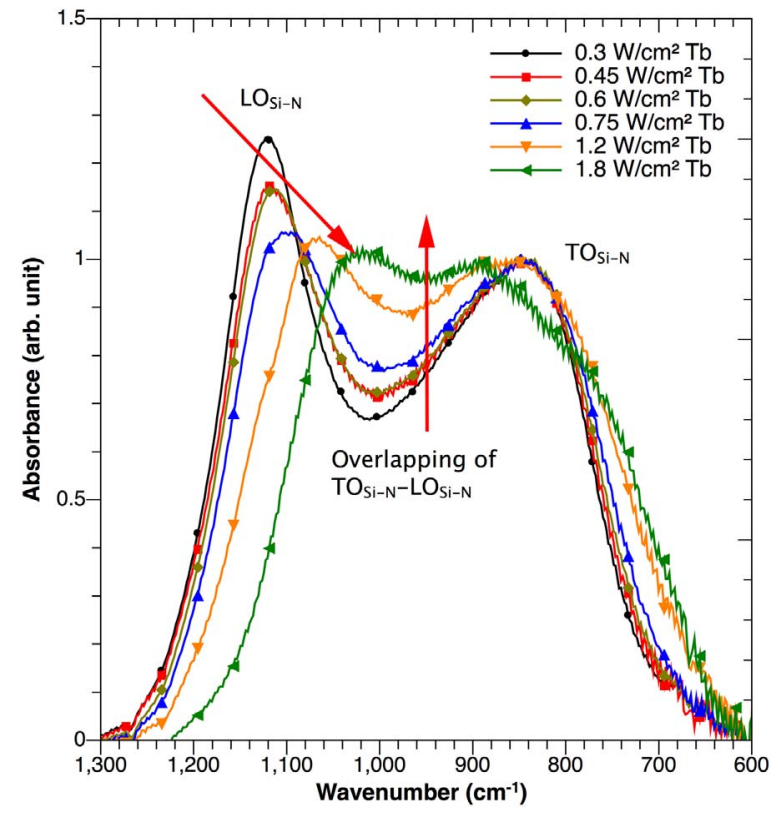

Fig. 13. FTIR spectra at Brewster angle of the Tb-doped $\mathrm{SiN}_{\mathrm{x}}$ layers for different $\mathrm{Tb}$ target $R F$ power densities.

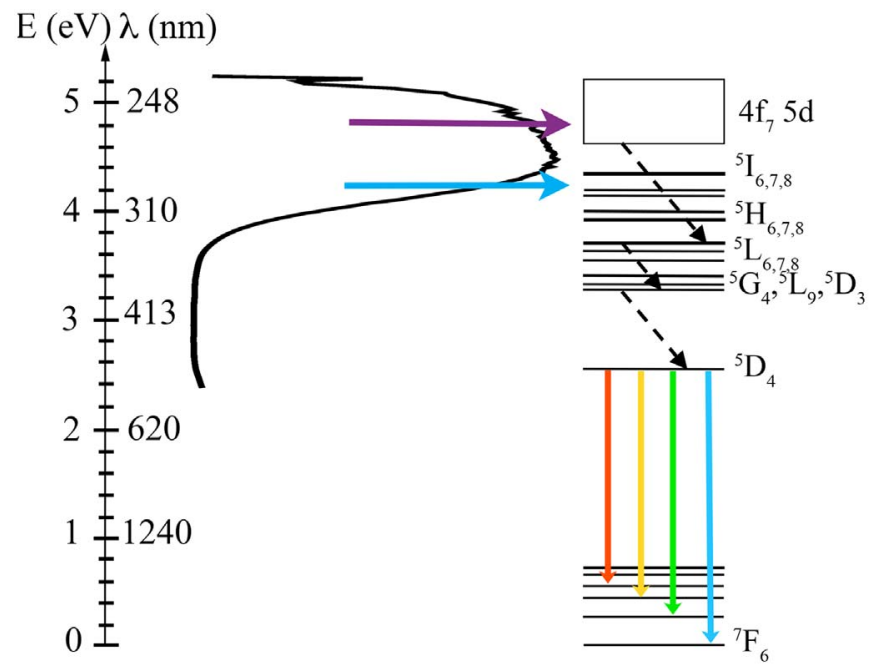

Fig. 14. PLE spectrum of the $\mathrm{SiN}_{\mathrm{x}}: \mathrm{Tb}^{3+}$ film for a detection wavelength of $545 \mathrm{~nm}$ and energy level diagram of the $\mathrm{Tb}^{3+}$ ion with the energy transfer from the matrix in blue and violet arrows, the non-radiative de-excitation in black straight dashed line arrows, and the radiative de-excitation in colored arrows. (For interpretation of the references to color in this figure legend, the reader is referred to the web version of this article).

$I_{\text {air }}^{P L}=C \frac{N^{*} \cdot V}{\tau_{\text {rad }}}$,

with $C$ an experimental constant, $V$ being the volume on which the $P L$ excitation is applied, $N^{*}$ being the excited state population density, and $\tau_{\text {rad }}$ being the $\mathrm{Tb}^{3+}$ radiative lifetime. In our experiment, the volume of interaction $\left(77.10^{-6} \mathrm{~mm}^{3}\right)$ and the pump power density $\Phi\left(1.9 \times 10^{15}\right.$ photons $/ \mathrm{cm}^{2}$ ) are constant. Assuming a constant $\tau_{\text {rad }}$ (around $620 \mu \mathrm{s}$ in both matrices) and a low pump power density approximation, we can express the excited state population density as:

$N^{*}=K \sigma \Phi \tau_{\text {rad }} N_{t o t}$

With $K$ an experimental constant, $N_{\text {tot }}$ the total population density of $\mathrm{Tb}^{3+}$ ions, and $\sigma$ the effective excitation cross-section.

Thus the ratio of the $P L$ intensities in the air can be written as (from Eqs. (4) and (5)):

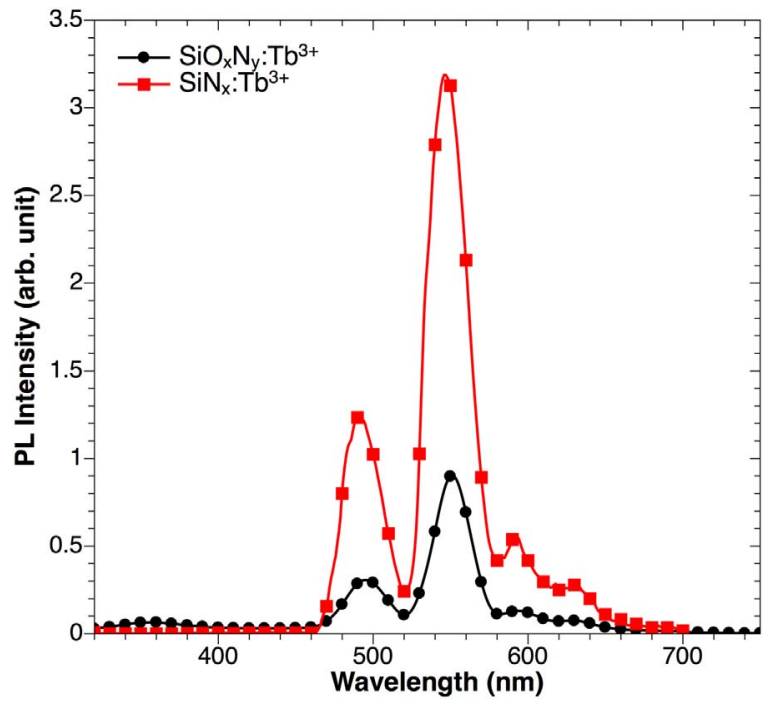

Fig. 15. Photoluminescence spectra of the optimized samples obtained of $\mathrm{Tb}^{3+}$-doped $\mathrm{SiO}_{\mathrm{x}} \mathrm{N}_{\mathrm{y}}$ and $\mathrm{SiN}_{\mathrm{x}}$ doped terbium matrices for a $285 \mathrm{~nm}$ excitation wavelength measured with the 600 lines/mm-750 bw grating.

$\frac{I_{\text {air }}^{P L}\left(\operatorname{SiN}_{x}\right)}{I_{\text {air }}^{\text {PL }}\left(\operatorname{Si} O_{x} N_{y}\right)}=\frac{N_{\text {tot }}\left(\operatorname{SiN}_{x}\right)}{N_{\text {tot }}\left(\operatorname{SiO}_{x} N_{y}\right)} \cdot \frac{\sigma_{\text {air }}\left(\operatorname{SiN}_{x}\right)}{\sigma_{\text {air }}\left(\operatorname{SiO}_{x} N_{y}\right)}=2.3$

RBS measurements on both layers are reported in the table as shown elsewhere $[26,47]$.

Thus, the ratio of total population densities is:

$\frac{N_{t o t}\left(\operatorname{SiN}_{x}\right)}{N_{t o t}\left(\operatorname{SiO}_{x} N_{y}\right)}=1.8$

The effective excitation cross-section in the air that represents the mechanisms of absorption and energy transfer between the matrix and the $\mathrm{Tb}^{3+}$ ions in the layer as well as the extraction of the $\mathrm{Tb}^{3+}$ emission (at $501 \mathrm{~nm}$ and $557 \mathrm{~nm}$ ) from this layer to the air. The ratio of such effective excitation cross-section of the $\mathrm{SiN}_{\mathrm{x}}$ matrix over the $\mathrm{SiO}_{\mathrm{x}} \mathrm{N}_{\mathrm{y}}$ one can thus be given by:

$\frac{\sigma_{a i r}\left(\operatorname{SiN}_{x}\right)}{\sigma_{\text {air }}\left(\operatorname{SiO}_{x} N_{y}\right)}=\frac{I_{\text {air }}^{P L}\left(\operatorname{SiN}_{x}\right) \cdot N_{\text {tot }}\left(\operatorname{SiO}_{x} N_{y}\right)}{I_{\text {air }}^{P L}\left(\operatorname{SiO} O_{x} N_{y}\right) \cdot N_{\text {tot }}\left(\operatorname{SiN}_{x}\right)}=1.3$

The ETMM program yields the integrated luminescence efficiencies $\eta^{\text {lum }}$ in the layer, in the air, and in the substrate. They are given in Table 2. We can see that the $\mathrm{SiN}_{\mathrm{x}}$ layer transfers more to the $S C$ (modeled here by the $\mathrm{Si}$ ) than the $\mathrm{SiO}_{\mathrm{x}} \mathrm{N}_{\mathrm{y}}$ layer.

The ratio of the effective excitation cross-section in the air (Eq. (8)) represents the $D S$ efficiency with extraction in the air. However for silicon solar cell applications, we may be interested in the $D S$ efficiency with extraction in the silicon $S C$. In order to evaluate this $D S$ efficiency with extraction in silicon, we use the Eqs. (3) and (8) and the integrated luminescence efficiencies of Table 2 to obtain the ratio of the effective excitation cross-section in the layer and in the substrate (Si-SC):

$\frac{\sigma_{i}\left(\operatorname{SiN}_{x}\right)}{\sigma_{i}\left(\operatorname{SiO} N_{x}\right)}=\frac{\eta_{i}^{\text {lum }} / \eta_{\text {air }}^{\text {lum }} \cdot \sigma_{\text {air }}\left(\operatorname{SiN}_{x}\right)}{\eta_{i}^{\text {lum }} / \eta_{\text {air }}^{\text {lum }} \cdot \sigma_{\text {air }}\left(\operatorname{SiO} O_{x} N_{y}\right)}$

This equation leads to a ratio of effective excitation cross-section of the $\mathrm{SiN}_{\mathrm{x}}$ matrix over the $\mathrm{SiO}_{\mathrm{x}} \mathrm{N}_{\mathrm{y}}$ one of 1.9 calculated in the layer and of

Table 1

Composition of the Tb-doped $\mathrm{SiN}_{\mathrm{x}}$ and $\mathrm{SiO}_{\mathrm{x}} \mathrm{N}_{\mathrm{y}}$ matrixes $[24,47]$.

\begin{tabular}{lllll}
\hline Samples & $\mathrm{Si}$ at $\%$ & $\mathrm{~N}$ at $\%$ & $\mathrm{~Tb}$ at $\%$ & $\mathrm{O}$ at $\%$ \\
\hline $\mathrm{SiN}_{\mathrm{x}}: \mathrm{Tb}^{3+}$ & 42 & 56 & 1.5 & - \\
$\mathrm{SiNxOy} \mathrm{Tb}^{3+}$ & 33 & 46 & 1 & 20 \\
\hline
\end{tabular}


Table 2

Integrated luminescence efficiencies of the $\mathrm{SiN}_{\mathrm{x}}$ and $\mathrm{SiO}_{\mathrm{x}} \mathrm{N}_{\mathrm{y}}$ matrixes in the air, the layer, and the silicon.

\begin{tabular}{llll}
\hline$\eta^{\text {lum }}(\%)$ & Air & Layer & Silicon \\
\hline $\mathrm{SiN}_{\mathrm{x}}$ & 8.7 & 56.3 & 35 \\
$\mathrm{SiN}_{\mathrm{x}} \mathrm{O}_{\mathrm{y}}$ & 13.8 & 60.2 & 26 \\
\hline
\end{tabular}

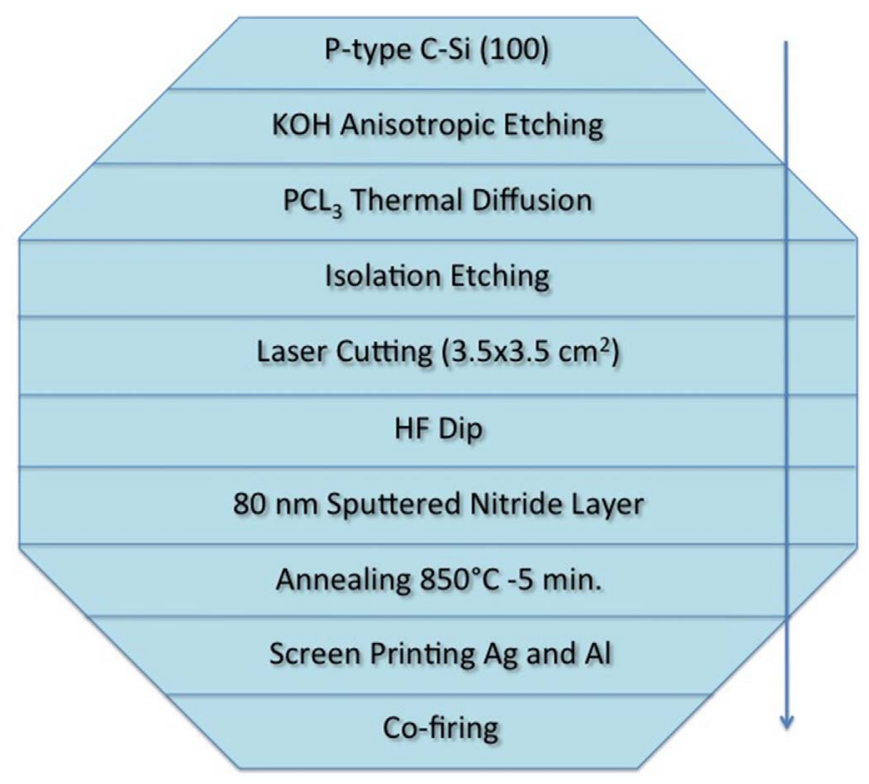

Fig. 16. Scheme of the process fabrication of the solar devices with the developed nitride layers.

\section{7 calculated in the substrate (Si-SC).}

This ratio shows the improvement of the DS efficiency of the $\operatorname{SiN}_{\mathrm{x}}$ layer compared to the thicker $\operatorname{SiN}_{\mathrm{x}} \mathrm{O}_{\mathrm{y}}$ one in the silicon. Part of this difference may be attributed to different thicknesses $(225 \mathrm{~nm}$ and $93 \mathrm{~nm}$ ) and different refractive indexes (1.65 and 2.02) for the $\mathrm{SiO}_{\mathrm{x}} \mathrm{N}_{\mathrm{y}}: \mathrm{Tb}^{3+}$ and $\mathrm{SiN}_{\mathrm{x}}: \mathrm{Tb}^{3+}$ respectively. For the conditions of thickness and refractive index employed in this work, the silicon, and thus the silicon solar cells, would receive 5 times more light at $501 \mathrm{~nm}$ and $557 \mathrm{~nm}$ from the $\mathrm{Tb}^{3+}$-doped $\mathrm{SiN}_{\mathrm{x}}$ layer compared to the $\mathrm{SiN}_{\mathrm{x}} \mathrm{O}_{\mathrm{y}}$ one. Thus the increase in the $P L$ intensity is due to two contributions: on one hand to the increase in the $\mathrm{Tb}^{3+}$ ions incorporation in the $\mathrm{SiN}_{\mathrm{x}}$ matrix without formation of clusters, and on the other hand to the improvement of the conversion efficiency of the layer.

\subsection{Device test}

The Si-based nitride layers described above have been deposited on top of industrial crystalline Si solar cells. For this purpose, its deposition step has been integrated in the industrial cells fabrication process. Fig. 16 describes schematically the steps followed that corresponds to the standard procedure of the Si-PV industry [51] with the integration of the deposition of our layer. A $200 \mu \mathrm{m}$-thick monocrystalline p-type Si wafer is chemically cleaned and textured using a $\mathrm{KOH}$ etching prior to operate a n-type doping via a $\mathrm{POCL}_{3}$ diffusion at $850{ }^{\circ} \mathrm{C}$ during $30 \mathrm{~min}$. Afterwards, an isolation etching process is performed for removing the $\mathrm{n}$-type $\mathrm{Si}$ at the edges and backsides. Thereafter a classical removed native oxide procedure is applied using a HF acid. Subsequently a 80 $\mathrm{nm}$-thick Si-based nitride layer is then deposited by means of $R F$ magnetron sputtering using the optimized fabrication conditions described above, before a post annealing treatment at $850{ }^{\circ} \mathrm{C}$ during $5 \mathrm{~min}$ to favor the recovering of non-radiative traps. The annealing time has been intentionally fixed at $5 \mathrm{~min}$ to avoid any damaging of the p-n junction through diffusion of the dopant. Then the last step of the process consists in screen-printing of Ag-front contacts and Al-back contacts followed by a co-firing.

A $\mathrm{Tb}^{3+}$-doped and undoped $\mathrm{SiN}_{\mathrm{x}}$ layers have been deposited to allow the observation of the rare earth doping effect on the optical properties of the device. Indeed, the standard anti-reflective layers of industrial solar cells are silicon nitride ones very close to our undoped layer. This undoped layer is thus used as a reference to determine the difference of efficiency brought by the deposition of the $D S$ layer on top of the cells.

Reflectance measurements have been carried out on the system before depositing the metallic contact (Fig. 17a). This optical characteristic plays an important role in a future solar device since our objective consists in optimizing the ARC layer (Anti-Reflective Coating). The Reflectance values for both nitride layers are below the value of $5 \%$ in wide domain of wavelength ranging from 350 to $750 \mathrm{~nm}$ and a bump is observed after $1020 \mathrm{~nm}$. The reflection efficiency in the $300-1200 \mathrm{~nm}$ range is of $6.04 \%$ for the device coated with the $\mathrm{SiN}_{\mathrm{x}}$ $A R C$ layer and reaches $6.20 \%$ by adding the rare earth ion. Such value demonstrates the high anti-reflective properties of the couple $A R C$ layer whatever the nitride layer deposited.

The study of the IQE spectra (Fig. 17b) reveals that the $\mathrm{Tb}^{3+}$-doped layer has a higher IQE than the undoped one from 300 to $900 \mathrm{~nm}$ with a
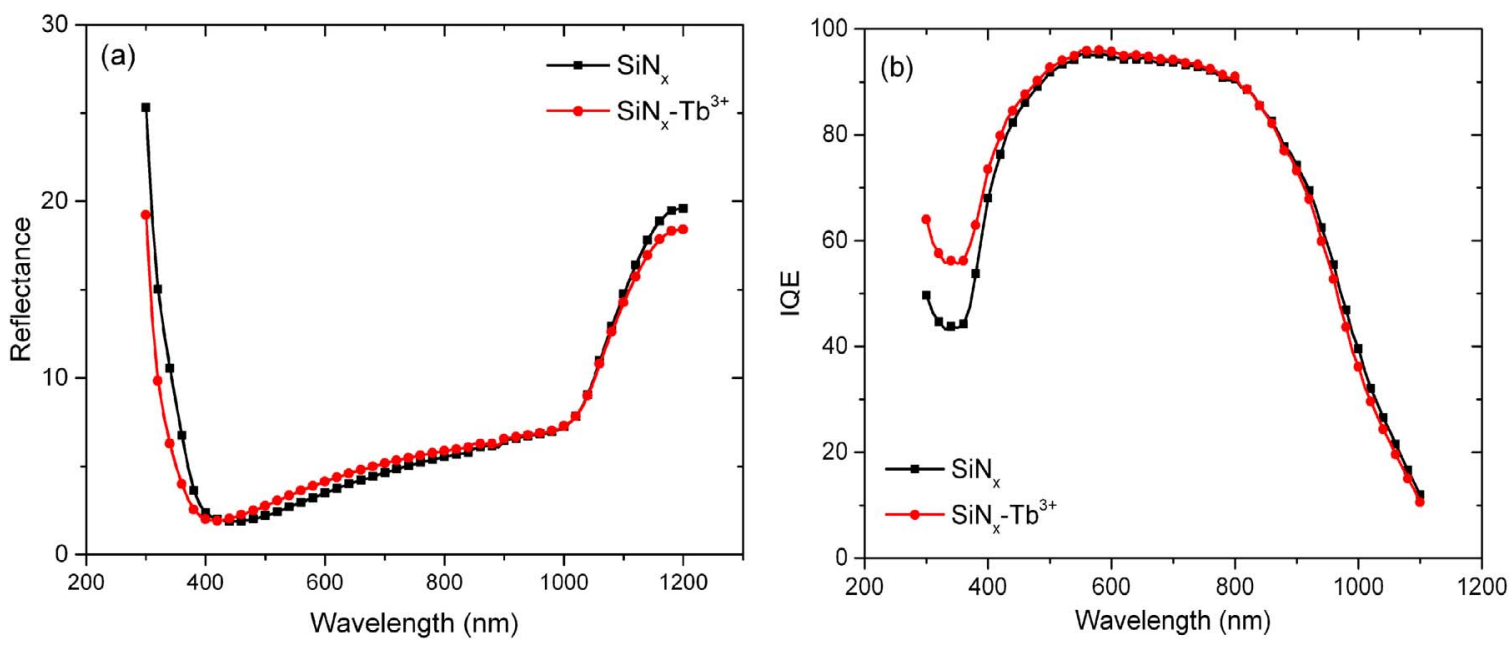

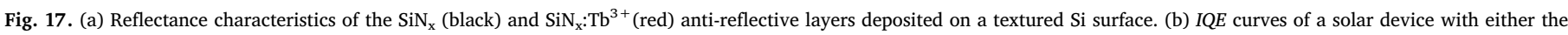

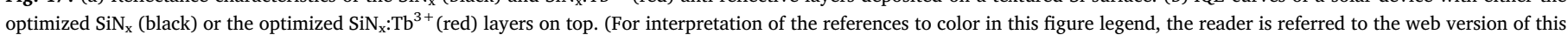
article). 
particular increase of $15 \%$ in the $U V$ range $(300-400 \mathrm{~nm})$. Above $900 \mathrm{~nm}$ one can note a slight decrease of the doped-layer with respect to the undoped one. This result shows that the $I Q E$ is larger for $U V$ photons thanks to the $\mathrm{Tb}^{3+}$-doped layer. In addition, Fig. $17 \mathrm{~b}$ displaying the reflectance of $S C$ topped with our layers (undoped- and $\mathrm{Tb}^{3+}$. doped-layers) shows that the $\mathrm{Tb}^{3+}$-doped layer has a lower reflectance in the $U V$ range which favors the absorption/or transmission of those photons by the layer/or to the cell. Regarding the IQE spectrum, the $\mathrm{Tb}^{3+}$-doped layer acts as a down-shifting layer that may improve the solar cell efficiency in the $U V$ part of the solar spectrum. This result shows that such $D S$ layer can be a promising solution for improving the Si-SC and that the process developed is fully compatible with the industrial process.

\section{Conclusion}

In this paper, both layers of $\operatorname{SiN}_{\mathrm{x}}$ and layers of $\mathrm{SiN}_{\mathrm{x}}: \mathrm{Tb}^{3+}$ deposited by reactive magnetron co-sputtering had been studied in order to obtain a thin down-shifting layer that emits a maximum at $629 \mathrm{~nm}, 594 \mathrm{~nm}$, $550 \mathrm{~nm}$, and $493 \mathrm{~nm}$ (terbium peaks) and is also an anti-reflective layer. Studies of the composition, the microstructure, and the optical properties enabled a better understanding of the requirements for obtaining such a layer. Comparing those studies with photoluminescence analyses leads to a better understanding of the properties needed to reach a high terbium emission. An optimized layer has been determined for a plasma pressure of 3 mTorr, a nitrogen ratio $r N_{2}$ of $20 \%$, and a $0.45 \mathrm{~W} / \mathrm{cm}^{2}$ power density on the terbium target. Such $\mathrm{SiN}_{\mathrm{x}}$-based optimized layer was found to transmit 5 times more down shifted light toward the solar cell than a comparable $\mathrm{SiO}_{\mathrm{x}} \mathrm{N}_{\mathrm{y}}$-based layer previously developed. For the monolithic crystalline Si solar cells with down-shifting layer, the IQE of the two optimized layers doped or not were compared. It was found that the down-shifting layer improves by $15 \%$ the IQE in the $U V$ part of the solar spectrum. The next step will consist in determining the optical-electrical characteristic of the solar cell with a downshifting layer on the top.

\section{Acknowledgments}

This work was financially supported by the French Research National Agency through the GENESE project ( $\mathrm{N}^{\circ}$ ANR-13-BS09-002001 ) and the LABEX EMC3 ASAP project. The French authors want to thanks the French ministry for the support through the Partenariat Hubert Curien (PHC) Programs Orchid $n^{\circ} 33572 X F$ and Polonium n²7720WC.

Lucile Dumont thanks CNRS and the Region Basse-Normandie for their PhD student support. In Poland, this work was funded by National Science Centre under Project No. DEC-2012/05/D/ST7/01121.

\section{References}

[1] E. Radziemska, The effect of temperature on the power drop in crystalline silicon solar cells, Renew. Energy 28 (2003) 1-12.

[2] E. Radziemska, E. Klugmann, Thermally affected parameters of the current-voltage characteristics of silicon photocell, Energy Convers. Manag. 43 (2002) 1889-1900, http://dx.doi.org/10.1016/S0196-8904(01)00132-7.

[3] P. Singh, S. Singh, M. Lal, M. Husain, Temperature dependence of I-V characteristics and performance parameters of silicon solar cell, Sol. Energy Mater. Sol. Cells 92 (2008) 1611-1616, http://dx.doi.org/10.1016/j.solmat.2008.07.010.

[4] E. Yablonovitch, Statistical ray optics, JOSA 72 (1982) 899-907.

[5] M.A. Green, K. Emery, Y. Hishikawa, W. Warta, E.D. Dunlop, Solar cell efficiency tables (Version 45): solar cell efficiency tables, Progress. Photovolt.: Res. Appl. 23 (2015) 1-9, http://dx.doi.org/10.1002/pip.2573.

[6] J. Zhao, M. Green, et al., Optimized antireflection coatings for high-efficiency silicon solar cells, IEEE Trans. Electron Devices 38 (1991) 1925-1934.

[7] M.C. Wei, S.J. Chang, C.Y. Tsia, C.H. Liu, S.C. Chen, $\mathrm{SiN}_{\mathrm{x}}$ deposited by in-line PECVD for multi-crystalline silicon solar cells, Sol. Energy 80 (2006) 215-219, http://dx.doi.org/10.1016/j.solener.2005.05.015.

[8] C. Strümpel, M. McCann, G. Beaucarne, V. Arkhipov, A. Slaoui, V. Švrček, C. del Cañizo, I. Tobias, Modifying the solar spectrum to enhance silicon solar cell efficiency-An overview of available materials, Sol. Energy Mater. Sol. Cells 91
(2007) 238-249, http://dx.doi.org/10.1016/j.solmat.2006.09.003.

[9] E. Klampaftis, D. Ross, K.R. McIntosh, B.S. Richards, Enhancing the performance of solar cells via luminescent down-shifting of the incident spectrum: a review, Sol. Energy Mater. Sol. Cells 93 (2009) 1182-1194, http://dx.doi.org/10.1016/j.solmat. 2009.02.020.

[10] B.S. Richards, Enhancing the performance of silicon solar cells via the application of passive luminescence conversion layers, Sol. Energy Mater. Sol. Cells 90 (2006) 2329-2337, http://dx.doi.org/10.1016/j.solmat.2006.03.035.

[11] F. Auzel, Upconversion processes in coupled ion systems, J. Lumin. 45 (1990) 341-345, http://dx.doi.org/10.1016/0022-2313(90)90189-I.

[12] A. Shalav, B.S. Richards, M.A. Green, Luminescent layers for enhanced silicon solar cell performance: up-conversion, Sol. Energy Mater. Sol. Cells 91 (2007) 829-842, http://dx.doi.org/10.1016/j.solmat.2007.02.007.

[13] K.D. Oskam, R.T. Wegh, H. Donker, E.V.D. van Loef, A. Meijerink, Downconversion: a new route to visible quantum cutting, J. Alloy. Compd., 300- 301 (2000) 421-425, http://dx.doi.org/10.1016/S0925-8388(99)00755-0.

[14] B.S. Richards, Luminescent layers for enhanced silicon solar cell performance: down-conversion, Sol. Energy Mater. Sol. Cells 90 (2006) 1189-1207, http://dx. doi.org/10.1016/j.solmat.2005.07.001.

[15] P. Würfel, Physics of Solar Cells: From Basic Principles to Advanced Concepts, WILEY-VCH, 2009.

[16] K.R. McIntosh, G. Lau, J.N. Cotsell, K. Hanton, D.L. Bätzner, F. Bettiol, B.S. Richards, Increase in external quantum efficiency of encapsulated silicon solar cells from a luminescent down-shifting layer, Progress. Photovolt.: Res. Appl. 17 (2009) 191-197, http://dx.doi.org/10.1002/pip.867.

[17] D. Chen, Y. Wang, Y. Yu, P. Huang, F. Weng, Quantum cutting downconversion by cooperative energy transfer from $\mathrm{Ce}^{3+}$ to $\mathrm{Yb}^{3+}$ in borate glasses, J. Appl. Phys. 104 (2008) 116105, http://dx.doi.org/10.1063/1.3040005.

[18] Q. Duan, F. Qin, D. Wang, W. Xu, J. Cheng, Z. Zhang, W. Cao, Quantum cutting mechanism in $\mathrm{Tb}^{3+}-\mathrm{Yb}^{3+}$ co-doped oxyfluoride glass, J. Appl. Phys. 110 (2011) 113503, http://dx.doi.org/10.1063/1.3662916.

[19] X. Liu, S. Ye, Y. Qiao, G. Dong, B. Zhu, D. Chen, G. Lakshminarayana, J. Qiu, Cooperative downconversion and near-infrared luminescence of $\mathrm{Tb}^{3+}-\mathrm{Yb}^{3+}$ codoped lanthanum borogermanate glasses, Appl. Phys. B 96 (2009) 51-55, http://dx. doi.org/10.1007/s00340-009-3478-z.

[20] D. Serrano, A. Braud, J.L. Doualan, W. Bolaños, R. Moncorgé, P. Camy, Two-step quantum cutting efficiency in $\mathrm{Pr}^{3+}-\mathrm{Yb}^{3+}$ codoped $\mathrm{KY}_{3} \mathrm{~F}_{10}$, Phys. Rev. B 88 (2013), http://dx.doi.org/10.1103/PhysRevB.88.205144.

[21] I.A.A. Terra, L.J. Borrero-González, T.R. Figueredo, J.M.P. Almeida, A.C. Hernandes, L.A.O. Nunes, O.L. Malta, Down-conversion process in $\mathrm{Tb}^{3+}-\mathrm{Yb}^{3+}$ co-doped Calibo glasses, J. Lumin. 132 (2012) 1678-1682, http://dx.doi.org/10. 1016/j.jlumin.2012.02.019.

[22] V.K. Tikhomirov, V.D. Rodríguez, J. Méndez-Ramos, J. del-Castillo, D. Kirilenko, G. Van Tendeloo, V.V. Moshchalkov, Optimizing Er/Yb ratio and content in Er-Yb co-doped glass-ceramics for enhancement of the up- and down-conversion luminescence, Sol. Energy Mater. Sol. Cells 100 (2012) 209-215, http://dx.doi.org/10 1016/j.solmat.2012.01.019.

[23] Y.-T. An, C. Labbé, M. Morales, P. Marie, F. Gourbilleau, Fabrication and photoluminescence properties of Tb-doped nitrogen-rich silicon nitride films, Phys. Status Solidi C. 9 (2012) 2207-2210, http://dx.doi.org/10.1002/pssc. 201200253.

[24] A. Podhorodecki, L.W. Golacki, G. Zatryb, J. Misiewicz, J. Wang, W. Jadwisienczak, K. Fedus, J. Wojcik, P.R.J. Wilson, P. Mascher, Excitation mechanism and thermal emission quenching of $\mathrm{Tb}$ ions in silicon rich silicon oxide thin films grown by plasma-enhanced chemical vapour deposition-Do we need silicon nanoclusters? J. Appl. Phys. 115 (2014) 143510, http://dx.doi.org/10.1063/1.4871015.

[25] C. Labbé, Y.-T. An, G. Zatryb, X. Portier, A. Podhorodecki, P. Marie, C. Frilay, J. Cardin, F. Gourbilleau, Structural and emission properties of $\mathrm{Tb}^{3+}$-doped nitrogen-rich silicon oxynitride films, Nanotechnology 28 (2017) 115710 (p. 14), http://dx.doi.org/10.1088/1361-6528/aa5ca0.

[26] L. Dumont, J. Cardin, P. Benzo, M. Carrada, C. Labbé, A.L. Richard, D.C. Ingram, W.M. Jadwisienczak, F. Gourbilleau, SiNx: $\mathrm{Tb}^{3+}-\mathrm{Yb}^{3+}$, an efficient down-conversion layer compatible with a silicon solar cell process, Sol. Energy Mater. Sol. Cells 145 (2016) 84-92, http://dx.doi.org/10.1016/j.solmat.2015.09.031.

[27] D.K. Sardar, K.L. Nash, R.M. Yow, J.B. Gruber, U.V. Valiev, E.P. Kokanyan, Absorption intensities and emission cross sections of $\mathrm{Tb}^{3+}\left(4 f^{8}\right)$ in $\mathrm{TbAlO}_{3}$, J. Appl. Phys. 100 (2006) 83108, http://dx.doi.org/10.1063/1.2358401.

[28] O. Debieu, R.P. Nalini, J. Cardin, X. Portier, J. Perrière, F. Gourbilleau, Structural and optical characterization of pure Si-rich nitride thin films, Nanoscale Res. Lett. 8 (2013) 1-13, http://dx.doi.org/10.1186/1556-276X-8-31.

[29] A.R. Forouhi, I. Bloomer, Optical dispersion relations for amorphous semiconductors and amorphous dielectrics, Phys. Rev. B 34 (1986) 7018-7026, http://dx.doi. org/10.1103/PhysRevB.34.7018.

[30] P. Yeh, Optical Waves in Layered Media, Wiley, New York, 1988.

[31] ASTM G173-03 (2012), Standard Tables for Reference Solar Spectral Irradiances: Direct Normal and Hemispherical on $37^{\circ}$ Tilted Surface, ASTM International, West Conshohocken, PA, 2012, 〈www.astm.org 〉.

[32] H. Benisty, R. Stanley, M. Mayer, Method of source terms for dipole emission modification in modes of arbitrary planar structures, JOSA A 15 (1998) 1192-1201.

[33] J.-P. Weber, S. Wang, A new method for the calculation of the emission spectrum of DFB and DBR lasers, IEEE J. Quantum Electron. 27 (1991) 2256, http://dx.doi.org/ $10.1109 / 3.97269$.

[34] Y.G. Boucher, Theoretical investigation of amplified spontaneous emission in an active structure by extended $(3 \times 3)$ transfer matrix formalism: the case of a nonuniform longitudinal distribution of emitters, J. Eur. Opt. Soc. - Rapid Publ. 1 (2006), http://dx.doi.org/10.2971/jeos.2006.06027.

[35] T. Li, J. Kanicki, Observation of incident angle dependent phonon absorption in 
hydrogenated amorphous silicon nitride thin films, Appl. Phys. Lett. 73 (1998) 3866, http://dx.doi.org/10.1063/1.122919.

[36] L. Huang, K.W. Hipps, J.T. Dickinson, U. Mazur, X.D. Wang, Structure and composition studies for silicon nitride thin films deposited by single ion bean sputter deposition, Thin Solid Films 299 (1997) 104-109, http://dx.doi.org/10. 1016/S0040-6090(96)09446-1.

[37] S. Hasegawa, L. He, Y. Amano, T. Inokuma, Analysis of SiH and SiN vibrational absorption in amorphous $\mathrm{SiN}_{\mathrm{x}}: \mathrm{H}$ films in terms of a charge-transfer model, Phys. Rev. B 48 (1993) 5315-5325, http://dx.doi.org/10.1103/PhysRevB.48.5315.

[38] W.R. Knolle, Correlation of refractive index and silicon content of silicon oxinitride films, Thin Solid Films 168 (1989) 123-132, http://dx.doi.org/10.1016/00406090(89)90695-0.

[39] J.G.E. Gardeniers, H.A.C. Tilmans, C.C.G. Visser, LPCVD silicon-rich nitride films for applications in micromechanics, studied with statistical experimental design, J. Vac. Sci. Technol. A 14 (1996) 2879-2892, http://dx.doi.org/10.1116/1.580239.

[40] M. Wang, M. Xie, L. Ferraioli, Z. Yuan, D. Li, D. Yang, L. Pavesi, Light emission properties and mechanism of low-temperature prepared amorphous $\mathrm{SiN}_{\mathrm{x}}$ films. I. Room-temperature band tail states photoluminescence, J. Appl. Phys. 104 (2008) 83504, http://dx.doi.org/10.1063/1.2996292.

[41] J. Kistner, X. Chen, Y. Weng, H.P. Strunk, M.B. Schubert, J.H. Werner, Photoluminescence from silicon nitride-no quantum effect, J. Appl. Phys. 110 (2011) 23520, http://dx.doi.org/10.1063/1.3607975.

[42] S.V. Deshpande, E. Gulari, S.W. Brown, S.C. Rand, Optical properties of silicon nitride films deposited by hot filament chemical vapor deposition, J. Appl. Phys. 77 (1995) 6534-6541, http://dx.doi.org/10.1063/1.359062.

[43] C. Mo, L. Zhang, C. Xie, T. Wang, Luminescence of nanometer-sized amorphous silicon nitride solids, J. Appl. Phys. 73 (1993) 5185-5188, http://dx.doi.org/10.
1063/1.353796.

[44] J. Robertson, M.J. Powell, Gap states in silicon nitride, Appl. Phys. Lett. 44 (1984) 415-417, http://dx.doi.org/10.1063/1.94794.

[45] W.L. Warren, J. Kanicki, J. Robertson, P.M. Lenahan, Energy level of the nitrogen dangling bond in amorphous silicon nitride, Appl. Phys. Lett. 59 (1991) 1699-1701, http://dx.doi.org/10.1063/1.106222.

[46] L. Zhang, H. Jin, W. Yang, Z. Xie, H. Miao, L. An, Optical properties of singlecrystalline $\alpha-\mathrm{Si}_{3} \mathrm{~N}_{4}$ nanobelts, Appl. Phys. Lett. 86 (2005) 61908, http://dx.doi.org/ 10.1063/1.1862753.

[47] Y.-T. An, C. Labbé, J. Cardin, M. Morales, F. Gourbilleau, Highly efficient infrared quantum cutting in $\mathrm{Tb}^{3+}-\mathrm{Yb}^{3+}$ codoped silicon oxynitride for solar cell applications, Adv. Opt. Mater. 1 (2013) 855-862, http://dx.doi.org/10.1002/adom. 201300186.

[48] D. Umamaheswari, B.C. Jamalaiah, T. Sasikala, T. Chengaiah, I.-G. Kim, L. Rama Moorthy, Photoluminescence and decay behavior of $\mathrm{Tb}^{3+}$ ions in sodium fluoro-borate glasses for display devices, J. Lumin. 132 (2012) 1166-1170, http:// dx.doi.org/10.1016/j.jlumin.2011.12.080.

[49] F. Benz, J.A. Guerra, Y. Weng, A.R. Zanatta, R. Weingärtner, H.P. Strunk, Concentration quenching of the green photoluminescence from terbium ions embedded in AlN and SiC matrices, J. Lumin. 137 (2013) 73-76, http://dx.doi.org/ 10.1016/j.jlumin.2012.12.028.

[50] D. Navarro-Urrios, Y. Lebour, O. Jambois, B. Garrido, A. Pitanti, N. Daldosso, L. Pavesi, J. Cardin, K. Hijazi, L. Khomenkova, F. Gourbilleau, R. Rizk, Optically active $\mathrm{Er}^{3+}$ ions in $\mathrm{SiO}_{2}$ codoped with $\mathrm{Si}$ nanoclusters, J. Appl. Phys. 106 (2009) 93107, http://dx.doi.org/10.1063/1.3253753.

[51] D.-H. Neuhaus, A. Münzer, Industrial silicon wafer solar cells, Adv. Optoelectron. (2007) 1-15, http://dx.doi.org/10.1155/2007/24521. 